\title{
MHC restriction and allogeneic immune responses
}

\author{
Dmitry B. Kazansky \\ Carcinogenesis Institute, N. N. Blokhin's Cancer Research Center, Moscow, Russia
}

\begin{abstract}
Discovery of major histocompatability complex (MHC) restriction helped in the understanding of how T-lymphocytes recognize antigens on bacteria, viruses, and tumor cells. It was initially accepted that MHC restriction was a consequence of "adaptive differentiation" in the thymus; during differentiation, the forming repertoire of T-lymphocytes "learned" a low affinity for self MHC molecules via positive selection. This view was later countered by discovery of artifacts in underlying studies and the fact that adaptive differentiation could not explain direct allogeneic and allorestricted recognition phenomena. Data from experiments with TCR transgenic animals, individual MHC/peptide complex expression, and recipients of xenogenic thymus glands yielded evidence of an ability to adapt to microenvironment and a low specificity of positive selection. These facts led to an alternative interpretation of $\mathrm{MHC}$ restriction explained, in part, by specificity of a pool of effector cells activated by primary immunization. Details of this phenomenon were defined in studies that noted differential primary structures of peptides that bound various allelic forms of MHC molecules. Here, the T-lymphocyte repertoire formed in the thymus was a result, in part, of random rearrangement of germinal sequences of TCR gene fragments. Such pre-selected repertoires were inherently capable of reacting with different allelic forms of MHC molecules. In contrast, MHC molecules were characterized by significant intraspecies polymorphisms; negative and positive selections were aimed at adaptation of a pre-selected repertoire to a specific microenvironment in an individual. Via elimination of autoreactive clones and sparing of a broad spectrum of specificity to potential pathogens, selection in the thymus could be considered a life-long allogeneic reaction of a pre-selected repertoire to self MHC molecules resulting in tolerance to "self," increased responsiveness to foreign MHC molecules, and crossreactivity of the mature T-lymphocyte repertoire to individual foreign peptides plus self MHC.
\end{abstract}

Keywords: Major histocompatibility complex, MHC restriction, alloreactivity, Tlymphocyte, repertoire, selection

\section{Discovery of MHC restriction}

Dependence of the immune response and immunorecognition on MHC Class I molecules was first shown in a lymphocytic choriomeningitis virus (LCMV) infection model (Zinkernagel and Doherty, 1973, 1974). As later noted, the basis for an MHC restriction hypothesis was development of a test for T-lymphocyte cytotoxicity against LCMV-infected cells. Doherty (using cerebrospinal liquor) and Zinkernagel (measuring cell cytotoxicity) saw that T-lymphocytes that specifically lysed infected targets were found in infected immunocompetent mice but not in nude mice, and that these cells were critical to disease pathogenesis. Still, it was critical for them to prove that immune splenocytes from other strains could kill infected cells with a respective MHC type. Using infected macrophages from varied strains as targets, it was seen that immune T-lymphocytes of $\mathrm{H}-2^{\mathrm{b}}$ mice lysed only infected cells from $\mathrm{H}-2^{\mathrm{b}}$ mice but had no effect on cells from hosts of a differing haplotype.

\footnotetext{
The author wishes to thank Professors Garry Abelev and Alexander Chervonsky whose helpful discussions initiated the writing of this manuscript. The author is very grateful to Professor Rolf Zinkernagel for providing some important references, and also wishes to thank Professor Alexander Shtil for being so helpful during the writing process. The work on recognition of MHC molecules by memory cells in the author's laboratory was supported by grants from the Russian Foundation for Basic Research, N-08-04-00563 and N-05-04-49793.

Address correspondence to Dr. Dmitry B. Kazansky, The Laboratory of Regulatory Mechanisms in Immunity, Carcinogenesis Institute, N. N. Blokhin's Cancer Research Center, Moscow, 115478, Russia; e-mail: kazansky@dataforce.net
} 
Dual specificity to MHC and virus was a pivotal finding that unveiled the role of MHC and explained T-lymphocyte responses to LCMV and other viruses. Shearer (1974) demonstrated preferential recognition of trinitrophenol (TNP)-labeled syngeneic targets by T-lymphocytes that were immune to TNP. Others proved the reproducibility of data using ectromelia and cowpox vaccine viruses (Blanden et al., 1975; Koszinowski and Ertl, 1975), H-Y antigen (Gordon et al., 1975), and minor histocompatibility antigens (Bevan, 1975); all contributed to a consensus that MHC-restricted recognition was not a casual event but, rather, a general mechanism.

The MHC-restricted manner of CTL-target interactions was subsequently expanded to helper cells, suggesting they too could recognize antigen-induced changes in MHC Class II on B-lymphocytes and macrophages. Most importantly, it became clear why MHC molecules were polymorphic: diversity minimized the opportunity for non-immunogenic molecule modification so that immunological tolerance of a population became improbable. By the mid-1980s, several studies noted that transplantation antigens encoded by MHC were antigen-presenting molecules and that they were recognized as complexes with antigenic peptides (Babbitt et al., 1985; Buus et al., 1986; Townsend et al., 1986; Maryanski et al., 1986).

\section{Origin of MHC restriction: adaptive differentiation or consequence of priming?}

"MHC restriction is an experimental observation of T-lymphocyte recognition of an antigen in association with particular MHC-encoded allelic product, but not with the product of another allele." This definition, provided by Schwartz (1984), echoed the intense discussions of the problem at that time-with the origins of MHC restriction being the most disputed.

Defenders of so-called adaptive differentiation ("ontogenetic model of MHC restriction") based their theory on T-lymphocyte recognition of MHC molecules in the body (Katz, 1977). Here, syngeneic MHC molecules restricted T-lymphocytes, as only the former were present during cell maturation. This theory was supported by experiments with bone marrow (BM) chimeras. After transplanting BM of $\mathrm{F}_{1}$ hybrids (after thorough removal of T-lymphocytes) into irradiated parent $(\mathrm{P})$ recipients (Bevan, 1977; Zinkernagel et al., 1978; Teh et al., 1982). The resulting chimerae bore hematopoietic cells from the donor $\left(\mathrm{F}_{1}\right)$, whereas other cells (including those from thymus) were of P1 origin. In these animals, the repertoire of mature T-lymphocytes was narrower than in donors, and the chimeras recognized mostly antigens in a context with recipient MHC molecules. Recipients responded mainly to antigens associated with their own MHC

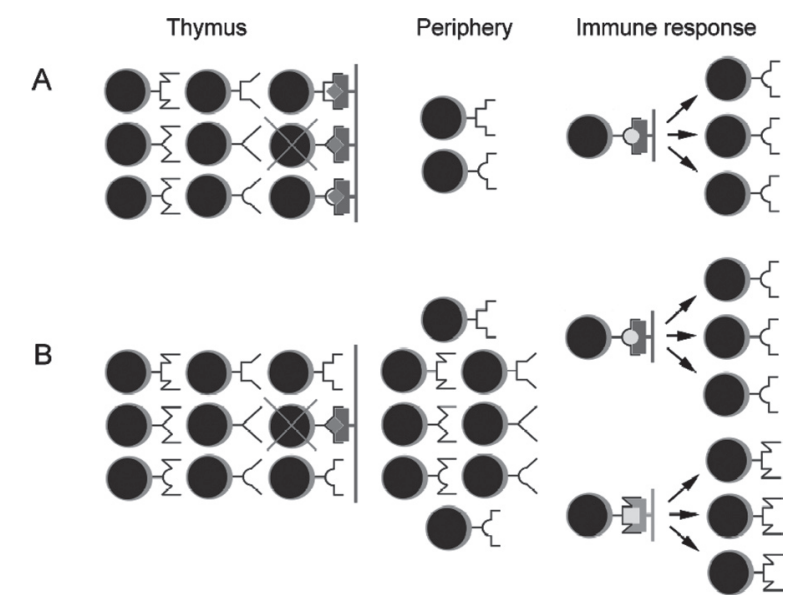

Figure 1. Difference between two concepts explaining origin of MHC restriction. (A) According to "adaptive differentiation" hypothesis, intrathymic development in contact with self-MHC (purple) presenting self-peptides (red diamonds) results in skewed diversity of T-lymphocytes learned to recognize external antigens (yellow circles) only in the context of self-MHC molecules. T-Lymphocytes not capable to interact with self $\mathrm{MHC} /$ peptides complexes undergo extensive "death by neglect." T-Lymphocytes interacting with "self" too well are subject of negative selection. (B) "Intentional priming" hypothesis assumes an existence of broad peripheral repertoire of T-lymphocytes. According to this hypothesis, MHC restriction is consequence of priming by particular combination of $\mathrm{MHC} /$ peptide, allowing responses to antigenic peptides (yellow) presented by self(purple) and foreign (green) MHC molecules.

(e.g., minor histocompatibility antigens and cowpox vaccine virus). This contradicted the "primary immunization model" wherein lymphocytes recognized antigen in a complex with MHC molecules of any haplotype (Stockinger et al., 1980; Wagner et al., 1981). Differences between the two models are shown in Figure 1.

The specificity of restriction of a T-lymphocyte repertoire in semi-allogeneic chimerae were largely dependent on the time course of appearance of BM-derived antigen-presenting cells (APC) in the recipient thymus. In the chimerae, donor type $\left(\mathrm{F}_{1}\right)$ APC could be found in the recipient $\left(\mathrm{P}_{1}\right)$ thymus 2 mo after BM transplantation. After depletion of peripheral T-lymphocytes, new T-lymphocytes that migrated from the thymus were restricted in MHC of both parents (Longo and Schwartz, 1980). It was eventually confirmed that positive selection in the thymus was not dependent on the thymic epithelium and could be regulated by other cell types (Bix and Raulet, 1992; Hugo et al., 1993). Moreover, selection could proceed without MHC molecules and did not require signaling via a co-receptor; the only requirement was a low affinity binding of TCR that caused no aggregation (Takahama et al., 1994). Despite some controversial results from among the radiation chimerae, the hypothesis of "adaptive differentiation in the thymus" became (and still is) generally accepted. 


\section{MHC restriction in nude mice: lessons from animals with knocked-out recombinates and aggregation chimerae}

The problem of MHC restriction in nude mice was thoroughly investigated in RAG knockout and TCR transgenic mice (Zinkernagel and Althage, 1999). In one series of studies, nude $\mathrm{F}_{1}\left(\mathrm{H}-2^{\mathrm{b}} \times \mathrm{H}-2^{\mathrm{d}}\right)$ were sublethally irradiated and then received embryonic $\mathrm{H}-2^{\mathrm{b}}$ RAG-1 or H-2 ${ }^{\mathrm{d}}$ SCID or H-2 ${ }^{\text {d }}$ RAG- $1^{0 / 0}$ thymic transplants. After $12-16 \mathrm{wk}$, the mice were immunized with LCMV; at Day 8, CTL restriction was tested and found to be restricted to thymic MHC molecules. These results showed that any "bias" of MHC restriction due to transplantation of thymocytes could not be associated with specific "suppressor mechanisms," as only immuno-deficient mice thymi were used for reconstitution.

In a second set of studies, $\mathrm{H}-2^{\mathrm{b}}$ mice were rescued with transplanted fully-allogeneic $\mathrm{H}-2^{\mathrm{k}}$ RAG- $1^{0 / 0}$ thymi. As before, CTL activity was restricted to MHC of the recipient but not those of the thymus. The authors were careful to point out that in radiation chimerae, a certain amount of hematopoietic cells could survive and influence positive selection. Along with the transplantation of allogeneic $\mathrm{H}-2^{\mathrm{k}} \mathrm{RAG}-1^{0 / 0}$ thymi, BM cells from the same immunodeficient donors were inoculated. Surprisingly, specificity of recipient T-lymphocytes (recipient were chimerae whose hematopoietic cells carried half-recipient $\backslash$ half-donor haplotypes) was restricted to MHC molecules of the donor and recipient and, in some cases, only to MHC molecules of the donor. The authors concluded that there was an alternative (if not major) way of selection and maturation of T-lymphocytes that depended on BM-derived cells.

Lastly, in these studies it was seen that MHC molecule expression in transplanted thymi used for $\mathrm{H}-2^{\mathrm{b}}$ reconstitution was not necessary for restoration of the T-lymphocyte repertoire. Transplantation of embryonic thymi from double Class I and II or $\beta 2$-microglobulin knockouts led to normal CTL responses to LCMV restricted to a $\mathrm{H}-2^{\mathrm{b}}$ haplotype. More surprisingly, the complete restoration of response was achieved after transplantation of thymi from xenogenic Lewis rats. Thus, the thymus acted mainly as an organ for differentiation, rearrangement, and expression of TCR genes. T-lymphocyte specificity reflected expansion of the repertoire and viability of T-lymphocytes on the periphery, as well as induction of effectors by MHC molecules on BM-derived cells.

Martinic et al. (2003) used aggregation allogeneic chimerae of 8-cell embryos, one of which contained a nude homozygote and another a RAG-1 ${ }^{0 / 0}$ or SCID

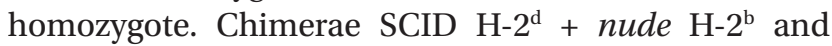
RAG- $1^{0 / 0} \mathrm{H}-2^{\mathrm{b}}+$ nude $\mathrm{H}-2^{\mathrm{d}}$ were obtained; thymic epithelium of the mice had the haplotype of MHC of SCID or RAG- $1^{0 / 0}$ embryo, whereas T- and B-lymphocytes originated from the nude embryo. These mice develop mixed chimerism in various tissues; among their leukocytes, $\mathrm{CD}^{+}, \mathrm{CD}^{+}$, and $\mathrm{B}^{2} 20^{+}$cells had nude haplotypes, whereas two $\mathrm{CD}_{11 \mathrm{~b}^{+} \text {macrophage populations }}$ expressed haplotypes of each parent. The thymuses of these chimerae bore normal cellular content and a well-differentiated epithelium with RAG- ${ }^{0 / 0}$ haplotype. To rule out thymic rudiments, double staining for MHC molecules (of RAG-1 ${ }^{0 / 0}$ ) and cytokeratin was performed. This indicated a thymus presence of non-epithelial (i.e., hematopoietic) cells with MHC molecules from a nude parent. None of the chimerae had thymic rudiments with mature epithelial cells carrying nude haplotype.

Infection of chimerae with LCMV and subsequent CTL responses to $\mathrm{H}-2^{\mathrm{b}}$ - and $\mathrm{H}-2^{\mathrm{d}}$-restricted peptides showed the T-lymphocyte repertoire of aggregation chimerae was restricted to MHC molecules of both parental haplotypes. The response was commensurate with that of wild type mice and led to complete viral clearance from the spleen. To better characterize the $\mathrm{CD}^{+}$effectors' repertoire, the cells were stained with MHC tetramers to show two distinct populations positive either for LCMV-GP33 $\left(\mathrm{H}-2 \mathrm{D}^{\mathrm{b}}\right)$ or for LCMV-NP118 $\left(\mathrm{H}-2 \mathrm{~L}^{\mathrm{d}}\right)$. Therefore, double restriction of repertoire was associated with real changes in specificity of restriction and not with cross-reactions.

As noted above, B-lymphocytes of the chimerae expressed MHC of the nude parent. This meant that in aggregation chimerae, $\mathrm{CD} 4^{+}$helper cells were restricted by non-thymic MHC molecules. Apparent contradictions with the results on semi-allogeneic radiation chimerae were explained by an incomplete elimination of TCR-interacting host cells after irradiation; thus, host T-lymphocytes survived regardless of location in the thymus or periphery. As proliferation in the thymus is very active, these host T-lymphocytes could gain an advantage over transplanted donor cells that must first migrate to the thymus. The aggregation chimerae are preferable because populations developing on thymic and nonthymic MHC are in "equal start" conditions (Martinic et al., 2003). In other words, early data on radiation chimerae were artifacts, and the ontogenetic model of MHC restriction was therefore doubtful. Most likely, this model held true only to the dependence of T-lymphocyte survival on the periphery on MHC molecules. Altogether, MHC restriction of the T-lymphocyte repertoire was regulated not as much as by the MHC haplotype of thymic epithelium, but by the haplotype of BM cells (probably, professional APC).

\section{Adaptive differentiation and positive selection: novel approaches}

Among findings underlying the ontogenetic model of MHC restriction were results showing that some Class II molecules could increase the frequency of 
peripheral T-lymphocytes expressing individual V $\beta$ regions (MacDonald et al., 1988; Blackman et al., 1989). Furthermore, blocking individual allelic MHC products in $F_{1}$ hybrids with allele-specific antibodies inhibited helper and CTL responses restricted to the blocked allele (Marrack et al., 1988; Marusic-Galesic et al., 1989). Importantly, absence of MHC Class I prevented CD8 ${ }^{+}$ formation, whereas absence of MHC Class II prevented $\mathrm{CD}^{+}$cell development (Koller et al., 1990; Zijlstra et al., 1990; Cosgrove et al., 1991; Grusby et al., 1991).

Mice with transgenic TCR develop a great number of T-lymphocytes with certain antigenic and restriction specificity. Initial studies about positive selection of transgenic H-Y TCR (specific for sex antigen peptide in the context of $\mathrm{H}-2 \mathrm{D}^{\mathrm{b}}$ ) (Kisielow et al., 1988; Teh et al., 1988), 2C (specific for H-2L ${ }^{d}$ ) (Sha et al., 1988) and AND (specific for pigeon cyt-c fragment in context of I-E $\mathrm{E}^{\mathrm{k}}$ ) (Berg et al., 1989; Kaye et al., 1989) allowed investigators to conclude that a mature T-lymphocyte with a transgenic receptor could develop in the presence of a restricting MHC allele and absence of specific peptide. This link was clearest in mice with transgenic TCR specific to H-Y antigen. Data demonstrated the link between positive selection and MHC restriction of the repertoire, i.e., showing positive selection of $\mathrm{CD}^{+}$with this TCR in the thymus of $\mathrm{RAG}^{0 / 0}$ $\mathrm{H}-2^{\mathrm{b} / \mathrm{d}}$ and no selection in the $\mathrm{RAG}^{0 / 0}$ thymus $\mathrm{H}-2^{\mathrm{d} / \mathrm{d}}$.

It eventually became apparent the ontogenetic viewpoint was idealized. Positive selection of $\mathrm{CD}^{+}$cells with transgenic $\mathrm{H}-\mathrm{Y}$ TCR in $\mathrm{H}-2^{\mathrm{b}}$ mice appeared associated with loss of $\mathrm{CD}^{+}$cells with the same receptor (Arsov and Vukmanovic, 1999). Studies of selection of 2C-TCR in wild type $\mathrm{B} 6$ mice, $\mathrm{K}^{\mathrm{b}}$ mutants, and hosts with initiallyexpressed $L^{\mathrm{d}}$ alloantigen revealed at least five phenotypic patterns of T-lymphocyte selection. These included: (1) positive selection ( $\mathrm{K}^{\mathrm{b}}$ and $\left.\mathrm{K}^{\mathrm{bm} 7}\right)$; (2) weak positive selection $\left(\mathrm{K}^{\mathrm{bm} 8}\right)$; (3) no positive selection ( $\mathrm{K}^{\mathrm{bml}}$ and $\left.\mathrm{K}^{\mathrm{bm} 10}\right)$; (4) negative selection of $\mathrm{CD} 8^{\mathrm{hi}}\left(\mathrm{K}^{\mathrm{bm} 3}\right.$ and $\left.\mathrm{K}^{\mathrm{bm} 11}\right)$; and, (5) negative selection of all $\mathrm{CD}^{+}$cells $\left(\mathrm{H}-2 \mathrm{~L}^{\mathrm{d}}\right)$. These results showed direct interaction of 2C-TCR with various MHC molecules during positive and negative selection (Sha et al., 1990).

In addition, 2C TCR recognized - besides the immunizingcomplexofL ${ }^{\mathrm{d}}$ pluspeptidep2Ca(LSPFPFDL)$\mathrm{K}^{\mathrm{bm} 3}$ plus peptide dEV8 (EQYKFYSV) and positivelyselecting $\mathrm{K}^{\mathrm{b}}$ molecule associated with peptide SIYR-8 (SIYRYYGL) (Tallquist et al., 1996; Udaka et al., 1992, 1996). Recognition of peptide antigens by this receptor was specific in the context of the allogeneic $\mathrm{L}^{\mathrm{d}}$ molecule, whereas in the context of positively-selecting $\mathrm{H}-2 \mathrm{~K}^{\mathrm{b}}$ molecule, all three peptides showed degenerative recognition (Tallquist et al., 1998). Moreover, positive selection of TCR could be observed in bm3 $\mathrm{TAP}^{0 / 0}$ mice, i.e., on "empty" heavy chains of $\mathrm{K}^{\mathrm{bm} 3}$ (Kuhns et al., 2000). It was also established that positive selection of T-lymphocyte receptor AND could proceed on different MHC alleles (Kaye et al., 1992).
Still, experiments with transgenic TCR seldom gave definitive results. Indeed, some TCR were positively selected by MHC alleles other than the restricting one, and positive selection of certain receptors was inefficient even by the selecting allele (Bogen et al., 1992). Also, narrowing of a repertoire to CD4 or CD8 cells was far from absolute (Kirberg et al., 1994; Matechak et al., 1996). Logunova gave an interesting example of such receptors by showing TCR MM14.4 obtained in responses of transgenic mice with a limited peptide repertoire presented to a syngeneic MHC Class II I-A $\mathrm{A}^{\mathrm{b}}$ molecule. Transfer of the transgene to wild type C57BL/6 mice led to deletion of T-lymphocytes with this receptor. Though the receptor was initially cloned from T-lymphocyte hybridoma $\mathrm{CD}^{+}$, predominantly $\mathrm{CD}^{+}$cells were positively selected in mice expressing the individual complex $\mathrm{A}^{\mathrm{b}}$ with an $\mathrm{E} \alpha$ chain AA52-68. In mice totally lacking MHC Class II, CD4 ${ }^{+}$cells were absent; in mice without $\mathrm{MHC}$ Class $\mathrm{I}, \mathrm{CD}^{+}$cells were absent. Positive selection of $\mathrm{CD} 4^{+}$T-lymphocytes with TCR MM14.4 was observed on three alleles of MHC Class II molecules: in BALB/c $\left(\mathrm{H}-2^{\mathrm{d}}\right), \mathrm{A}_{\beta}{ }^{\mathrm{bm} 12}$ mutants and DM knockouts with $\mathrm{A}^{\mathrm{b}}$ complexed with CLIP peptide of invariant chain (li). These facts suggested degenerative recognition of MHC molecules during positive selection.

Other studies of "specificity" of positive selection were aimed at generating transgenic mice expressing individual MHC/peptide. The net results were that limitation of the presenting peptide repertoire lowered the efficiency of positive selection and presentation of endogenous superantigens (Golovkina et al., 2001). Nevertheless, selection of a diverse repertoire of T-lymphocytes occurred in these mice, and T-lymphocytes were capable of reacting on different allelic MHC molecules (Ignatowicz et al., 1996, 1997; Chmielowski et al., 1999; Lee et al., 1999). Based on all the above, it was concluded that positive selection of a repertoire was due to degenerative recognition of endogenous $\mathrm{MHC} /$ peptide complexes. Though efficacy can depend on variety of peptides associated with "self" MHC molecules, positive selection cannot determine the restriction specificity of the forming T-lymphocyte repertoire.

\section{Allorestricted recognition as evidence in support of "priming" hypothesis}

The most critical conclusion of the "adaptive differentiation" hypothesis-after experiments with semi-allogeneic chimerae-was that MHC restriction was a process adopted by T-lymphocytes during antigen-independent differentiation in a thymus. This "narrowed" a lymphocyte repertoire to the extent that only clones specific to antigen associated with self-MHC molecules proliferated in response to antigen. Therefore, this model presumed that non-immune T-lymphocytes did not recognize the antigen associated with allogeneic MHC molecules. This 
contrasted with the "priming" hypothesis that surmised that T-lymphocyte clones recognized antigen associated with allogeneic MHC molecules. The question arising from this collision of hypotheses was whether allorestricted recognition exists.

Using the method of limiting dilutions, the frequency of auto- and allorestricted CTL in this depleted population was determined. The frequency of precursors with syngeneic restriction was $\approx 6$ times higher than that of precursors with allogeneic restriction. This difference fluctuated from 2-10-fold depending on inbred strain combination (Stockinger et al., 1980; Wagner et al., 1981). Similar results were observed for precursors of thymus CTL devoid of alloreactive cells and recognizing TNP derivatives in the context of syngeneic and allogeneic MHC molecules (Stockinger et al., 1981).

Wagner et al. (1981) were correct to suggest that a preference of the T-lymphocyte repertoire for antigen recognition in the context of "self" MHC could be a consequence of an experimental procedure and breaking normal repertoire during the course of chimerism formation or depletion of alloreactive cells. This was verified in subsequent studies that determined frequencies of allorestricted clones in the repertoire of normal allogeneic mice. Using combinations of allogeneic strains, it was seen that stimulation of CTL precursors with TNFmodified allogeneic cells caused unusually high frequencies of clones that react with these CTL $(1 / 30-1 / 300)$; CTL reacting clones did not react with non-modified allogeneic targets (Reimann et al., 1985a). The responses of combinations of $\mathrm{B} 6$ and bml stimulators and responders to herpes simplex virus and TNP derivatives showed that $\approx 30 \%$ of reacting clones recognized their targets in an allorestricted manner, i.e., they did not react with non-infected or non-modified targets (Reimann et al., 1985b). Kabelitz et al. (1987) proved the existence of allorestricted T-lymphocytes in humans that responded to parotitis virus.

Restriction of allorestricted T-lymphocyte responses to MHC molecules absent in the thymus was used to obtain high avidity clones capable of recognizing tumorassociated antigens in patients. Indeed, normally negative selection ablates high avidity lymphocyte clones that can react with self antigens of an organism (P1) in the context of self MHC molecules (H-2 $\left.2^{\mathrm{x}}-\mathrm{P} 1\right)$. But the clones specific to $\mathrm{H}-2^{\mathrm{x}}-\mathrm{P} 1$ could be presented in an allogeneic $\mathrm{P} 2$ because negative selection deleted the clones specific to tumor-associated antigens in the context of "another self" MHC (H-2 $\left.{ }^{\mathrm{y}}-\mathrm{P} 2\right)$. Thus, allorestricted recognition could supposedly provide a basis to obtain clones of $\mathrm{P} 2$ specific to a combination of MHC molecule with $\mathrm{H}-2^{\mathrm{x}}-\mathrm{P} 1$ peptide (for adoptive immunotherapy).

Sadovnikova and Stauss (1996) generated allorestricted CTL clones of $\mathrm{H}-2^{\mathrm{d}}$ mice, thereby demonstrating successful use of allorestricted recognition of tumor-associated antigens. These clones were specific to a complex of $\mathrm{H}-2 \mathrm{~K}^{\mathrm{b}}$ plus mdm-2-derived peptide; it is noteworthy that mdm-2 is often over-expressed in tumor cells. In culture, these clones selectively reacted with, and killed, melanoma and lymphoma cells - but not normal $\mathrm{H}-2 \mathrm{~K}^{\mathrm{b}}$-expressing dendritic cells. In vivo, allorestricted clones caused retardation of the growth of melanoma and lymphoma cells in syngeneic $\left(\mathrm{H}-2^{\mathrm{b}}\right)$ recipients (Stanislawski et al., 2001). The authors also attempted to obtain allorestricted clones specific to a cyclin D1 peptide in the context of human HLA-A2. The clones lysed cyclin D1-over-expressing breast carcinoma cells, but not Epstein-Barr-transformed lymphoblastoid cells (Sadovnikova et al., 1998). Thus, allorestricted recognition became an efficient means of breaking tolerance to tumor-associated antigens and to get responses to leukemia-associated markers like WT1, CD68 and CD45 (Gao et al., 2000; Sadovnikova et al., 2002; Amrolia et al., 2003).

An additional significant impact on the theory of allorestriction was made in studies that identified MHC binding motifs in peptides that interact with allele-specific forms of MHC molecules. Obst et al. (1998) stimulated a repertoire of T-lymphocytes $\mathrm{H}-2^{\mathrm{d}}$ with a mixture of synthetic peptides from combinatorial libraries of peptides that had an MHC binding motif for interaction with $\mathrm{H}-2 \mathrm{~K}^{\mathrm{b}}$, and cells lacking TAP (to present the synthetic peptides on APC). Incubation of the cells with peptides whose structures were optimal for binding with MHC resulted in successful formation of an MHC molecule $/ \beta_{2}-$ microglobulin/peptide complex and subsequent transport onto the plasma membrane. Allorestricted, as well as autorestricted, CTL lines obtained in response to such cells widely varied in their peptide specificity and avidity. The authors concluded that positive selection in the context of certain MHC molecule was not required for generating high avidity TCR restricted to the same molecule, but increased the frequency of these CTL. The authors also analyzed precursors of allorestricted CTL in peripheral blood of HLA-A2 ${ }^{-}$and HLA-A3 donors. It was noted that TAP- targets that expressed these HLA (after incubation with combinatorial peptide libraries bearing proper MHC binding motifs) induced responses. CTL specific to these peptide libraries in the context of allogeneic MHC molecules comprised a major part of the repertoire. However, the frequency of allo-restricted CTL was two times lower than that of CTL restricted to self-MHC molecules.

Any links between self-MHC expression and alloreactive $\backslash$-restricted repertoires was subsequently studied. The approach used was as above, plus testing allorestricted responses to viral and self peptides. It was noted that the closer the structures of allogeneic MHC molecule and T-lymphocyte MHC molecule were, the greater the ratio of allorestricted CTL that recognize 
antigen peptides:CTL recognizing the allogeneic molecule independently of the peptide. As expected, the highest ratio of peptide-specific clones was found in a response to $\mathrm{H}-2^{\mathrm{b}}$ stimulators of mutant bm13 and bml4 with the mutations in the $\mathrm{H}-2 \mathrm{D}^{\mathrm{b}}$ antigen-binding groove. This link could be associated with effects on the alloreactive repertoire of positive selection in the thymus and lymphocyte survival in periphery. However, this did not prohibit recognition of peptides in an allogeneic context (Obst et al., 2000). Using MHC tetramer technology, allorestricted T-lymphocytes that specifically recognize antigenic peptides were later isolated (Moris et al., 2001).

It was thus concluded that T-lymphocytes recognize antigens in the context of MHC molecules absent during thymocyte differentiation. The existence of lymphocytes capable of recognizing antigens in the context of allogeneic MHC molecules was by itself a solid argument against an ontogenetic origin of MHC restriction. Evidently, positive selection in the thymus, and T-lymphocyte survival on the periphery, have low impact on formation of MHC-restriction. This makes the concept of adaptive differentiation inappropriate to explain the early experimental results of Zinkernagel and Doherty.

\section{The molecular basis of MHC restriction: MHC binding motifs}

Can primary priming explain difficulties and controversies in data that adaptive differentiation cannot? Dependence of repertoire restriction on the replacement of host APC with donor cells in radiation chimerae (Longo and Schwartz, 1980) and the simultaneous transplantation of the thymus and BM from RAG knockouts into nude mice (Zinkernagel and Althage, 1999) led to an assumption that MHC restriction was controlled at the level of antigen presentation. Indeed, measures of specific functions of effector cells always required antigen priming of the naive T-lymphocytes. The "non-thymic cells from BM" that partook in immune responses were professsional APC, i.e., dendritic cells, B-lymphocytes, macrophages. Differing life spans of these cells after lethal irradiation and different roles in immune responses might have been a source of experimental artifact and misinterpretation. Conversely, it was evident that primary responses (i.e., allogeneic response, reaction to bacterial superantigens) were MHC-unrestricted.

Rammensee's group uncovered how APC determined restriction of effector lymphocytes. As noted in a review on MHC binding motifs in antigens (Rammensee, 1995), Rotzschke and Falk made this discovery in studies that examined the structures of peptides that interact with Class I MHC molecules. The isolated peptides revealed invariant amino acid (AA) residues near the C- and $\mathrm{N}$ - termini. Importantly, peptides bound by different allelic forms of MHC Class I molecules had similar lengths but different allele-specific motifs (Falk et al., 1990, 1991a; Rotzschke et al., 1990). These studies showed that one could identify allele-specific sequences from among the huge variety of peptides derived from one antigenic protein (Falk et al., 1991a, 1991b).

These motifs formed by "anchoring" AA residues necessary for high affinity binding of the peptide to respective MHC also indicated that APC expressing different MHC haplotypes would present various peptides of the same antigen. For example, influenza virus nucleoprotein contains an epitope that binds $\mathrm{H}-2 \mathrm{~K}^{\mathrm{d}}$ in positions AA147-155 (TYQRTRALV) and H-2D ${ }^{\mathrm{b}}$ in positions AA366374 (MTEMNENSA). For human MHC, the epitope for binding HLA-A2 is within AA85-94 (KLGEFYNQM),

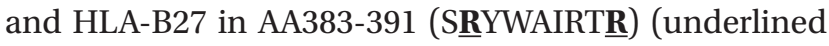
= anchoring [motif-forming] residues). Mechanisms of peptide/MHC molecule association allowed for predicting the structure of lymphocyte peptide epitopes, including tumor antigens (Rotzschke et al., 1991; Wallny et al., 1992; Rammensee et al., 1993). Further, these studies established a molecular basis for an association between autoimmune diseases and certain MHC haplotypes (Vartdal et al., 1996; Kalbus et al., 2001; Munz et al., 2002). Finally, the ability of individual allelic products of MHC molecules to bind particular peptides of the pathogen directly linked MHC with genetically determined immune responses to pathogens.

The Rammensee group also discovered the molecular mechanism of MHC restriction. In initial experiments, immunization of $\mathrm{CBA}\left(\mathrm{H}-2^{\mathrm{k}}\right)$ mice with LCMV induced CTL that recognized viral peptides with $\mathrm{MHC} \mathrm{H}-2^{\mathrm{k}}$ binding motifs. Clearly, these specific CTL lysed infected L929 cells/macrophages $\left(\mathrm{H}-2^{\mathrm{k}}\right)$ that presented the same viral peptides. These CTL did not kill infected macrophages of $\mathrm{H}-2^{\mathrm{d}}$ haplotype that presented totally different peptides of the virus. This was shown in analyses of immunogenicity of three LCMV epitopes restricted by the H-2D ${ }^{\text {b }}$ molecule, i.e., GP33-41 (KAVYNFATC), GP276-286 (SGVENPGGYCL), NP396-404 (FQPQNGQFI). Efficacy of presentation of these peptides correlated with intensity of the antiviral CTL response. The NP396-404 peptide (bearing two anchoring residues for $\mathrm{H}-2 \mathrm{D}^{\mathrm{b}}$ binding) showed the highest protective effect, regardless of its relatively low levels on APC (Gallimore et al., 1998).

\section{Origins of allogeneic response: direct and indirect recognition}

All transplantation antigens fall into two categories: major (i.e., classical H-2-encoded MHC molecules) and minor histocompatibility antigens, i.e., other polymorphic transplantation antigens. The allogeneic MHC molecules are most important for rejection of a transplant. It was seen early on that a transplant bearing foreign $\mathrm{MHC}$ was rejected within 8-10 d, whereas one with alien minor 


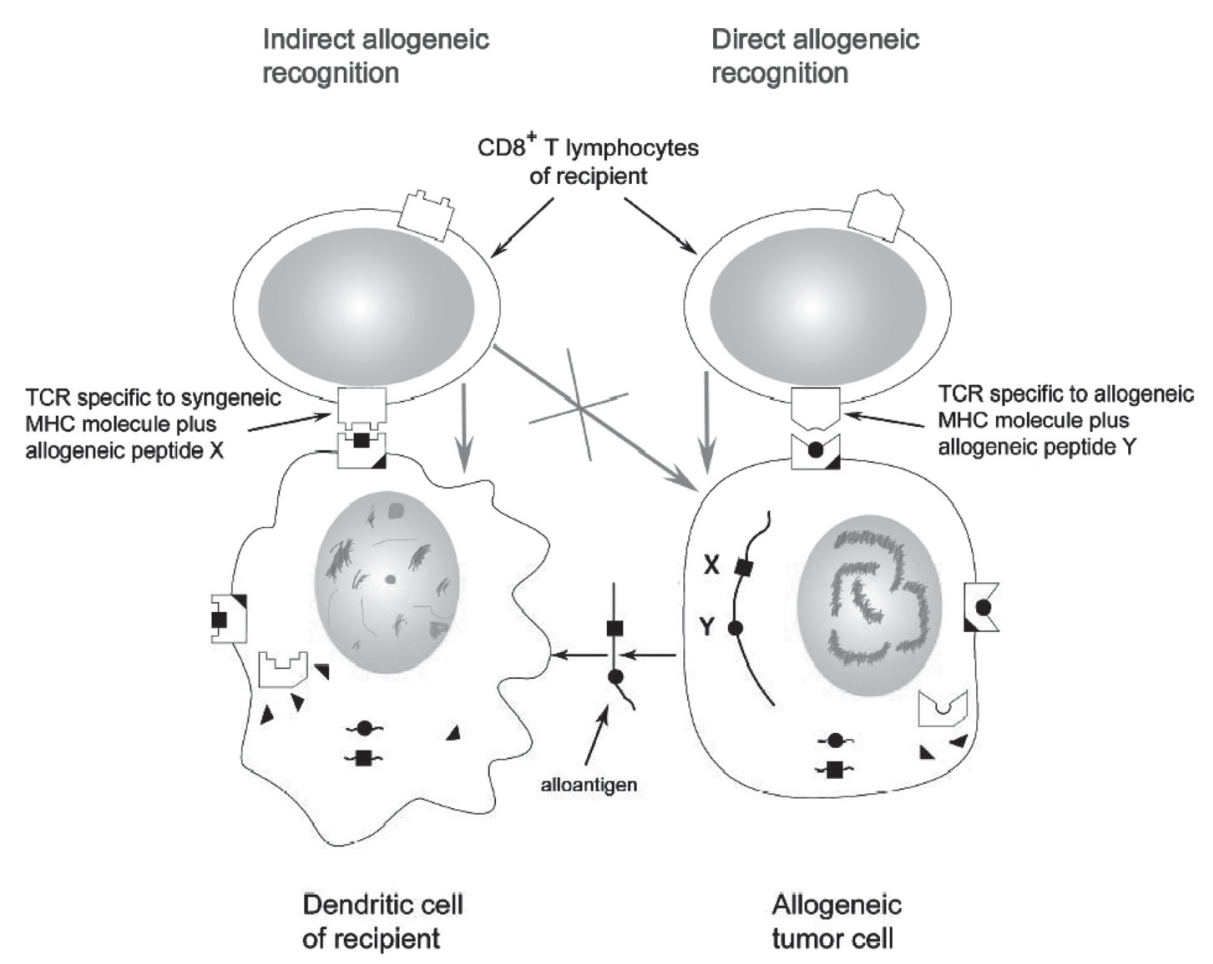

Figure 2. Direct and indirect recognition of allogeneic tumor cells. Rejection of allogeneic tumors represents a basic phenomenon of transplantational immunology and immunogenetics, which cannot be fully explained in frames of current immunological paradigm. To destroy allogeneic tumor cells, CTL should react to allogeneic MHC Class I molecules, not expressed on recipient's professional APC, whereas cross-priming by self-APC should result in induction of CTL destroying self-APC presenting foreign peptides (black squares) but sparing engrafted tumor cells expressing foreign MHC alleles and presenting unrelated peptides (black circles). In reality, in response to allogeneic tumor cells we obviously see selective expansion of CTL directly reacting with allogeneic MHC molecules on tumor cells. Blue arrows show the direction of killing.

antigens remained viable at least $3 \mathrm{wk}$. MHC alloantigens induced very strong T-lymphocyte responses in culture (i.e., $1^{\circ}$ responses), while responses to conventional antigens (i.e., ovalbumin) required pre-immunization. Further, alloreactive precursors were more frequent than cells specific to antigens presented with self-MHC molecules. The frequency of alloreactive lymphocytes was seen to be as high as $2-5 \%$ of the total T-lymphocyte population, whereas cells that react to soluble/viral antigens were normally 1:10,000 (Fischer et al., 1977).

Two models explain T-lymphocyte alloantigen recognition. Direct allogeneic recognition presumed interaction of T-lymphocyte receptor with an allogeneic MHC molecule bound to the peptide from allogeneic APC. After grafting, this response was mediated by migration of donor APC to the recipient's lymphoid tissue. This explained how the allogeneic response was not MHCrestricted and was in concert with a dominant genetic control of inducibility. Indirect allogeneic recognition implied the allogeneic peptide was recognized by T-lymphocytes bound to an MHC of the recipient and functioned in responses to minor histocompatibility antigens, and was MHC-restricted (inheritance being co-dominant). This mode of recognition was a result of presentation of allogeneic peptides derived from the graft by the recipient's dendritic cells. After engulfment, graft proteins could be processed for presentation in the context of recipient MHC Class II or transferred into endoplasmic reticulum to be associated with Class I molecules for further cross-priming of recipient T-lymphocytes (Bevan, 1976; Benichou et al., 1999; Gould and Auchincloss, 1999).

Hypothesis of adaptive differentiation was in agreement only with the second model, whereas primary priming was in concert with both models. According to adaptive differentiation, allogeneic recognition must be a consequence of recognition of allogeneic peptides in the context of self-MHC of the responder. Direct interaction with allogeneic MHC molecules can occur only as a random cross-reaction of T-lymphocyte receptors "instructed" to react with self-MHC.

To demonstrate indirect recognition, donor APC lysates were added to a MLR (i.e., a setting wherein direct presentation of antigen was impossible). Lysed APC of MHC-incompatible donors induced T-lymphocyte proliferation in the mixed lymphocyte cultures. However, this effect was detectable only after preliminary immunization of the recipients and not confirmed by: inhibition with antibodies against presenting MHC allele; use of APC from MHC-deficient mice; or, APC from recombinant mice that express other presenting alleles, factors that would bolster an indirect mechanism. Moreover, no 
phenotyping of proliferating cells was performed due to a certitude that the $a$ priori proliferating cells were $\mathrm{CD} 4^{+}$ (Gould and Auchincloss, 1999).

To study responses to allogeneic Class I MHC, we have used a similar system in which C57BL/10 (H-2 $\left.2^{\mathrm{b}}\right)$ mice were immunized with P815 mastocytoma (H-2 $\left.{ }^{\mathrm{d}}\right)$ cells (Kazansky et al., 1998, 1999). Re-stimulation during in vitro MLR was performed 2 mo later using heatshocked stimulator splenocytes of $\mathrm{C} 57 \mathrm{BL} / 10\left(\mathrm{H}-2^{\mathrm{b}}\right)$, B10.D2 or BALB/c $\left(\mathrm{H}-2^{\mathrm{d}}\right)$, and $\mathrm{C} 3 \mathrm{H}\left(\mathrm{H}-2^{\mathrm{k}}\right)$ mice. Primary proliferative response to dead allogeneic APC should have been absent. Dead allogeneic APC triggered T-lymphocyte proliferation of pre-immunized recipients; however, in response to immunizing antigen, only $\mathrm{CD}^{+}$ cells of immune animals proliferated. Similar results were obtained in a system with B10.D2 (R101) $\left(\mathrm{K}^{\mathrm{d}} \mathrm{I}^{\mathrm{d}} \mathrm{D}^{\mathrm{b}}\right)$ mice immunized with EL4 $\left(\mathrm{H}-2^{\mathrm{b}}\right)$ cells, followed by re-stimulation during in vitro MLR with heated splenocytes from B10.D2 (R101), C57BL/6 (H-2 $\left.{ }^{\mathrm{b}}\right)$, and $\mathrm{C} 3 \mathrm{H}$ $\left(\mathrm{H}-2^{\mathrm{k}}\right)$ mice. It was noted that the ability to proliferate in response to dead allogeneic APC was not a consequence of indirect recognition of the alloantigen but, rather, a specific feature of $\mathrm{CD}^{+}$memory cells primed by the antigen and trans-co-stimulated.

The tumor cells used were not professional APC, so primarily indirect recognition of the alloantigen by $\mathrm{CD} 4^{+}$cells could be expected. However, only $\mathrm{CD}^{+}$cells proliferated. Primed $\mathrm{CD} 8^{+}$cells recognized the antigen directly because proliferation of R101 mouse memory cells was blocked by antibody to $\mathrm{H}-2 \mathrm{~K}^{\mathrm{b}}$ and because the response was absent if stimulation in MLR was performed with cells from TAP and $\beta_{2}$-microglobulin knockouts on a C57BL/6 (H-2 $\left.2^{\mathrm{b}}\right)$ background (Kazansky et al., 1999; Pobezinskaya et al., 2004). Thus, even if indirect recognition of allogeneic Class I MHC was favored (immunization with non-professional tumor $\mathrm{APC}), \mathrm{CD}^{+}$cells directly interacting with foreign MHC Class I were a major component of the response.

\section{Direct allogeneic recognition: peptides or side chains?}

"Initial priming" explained alloreactivity as a consequence of an innate preference of T-lymphocyte receptors to recognize MHC molecules of a species/a higher density or frequency of allogeneic determinants presented by allogeneic MHC. Jerne (1971) was first to provide a hypothesis of evolutionary preference of TCR genes according to their products' ability to interact with MHC molecules of the same species. This suggested that after intrathymic elimination of self-reactive T-lymphocytes, a repertoire was left that comprised of a high frequency of cells specific to all other MHC antigens. As selection led to enrichment of T-lymphocytes able to react with MHC, the TCR gene pool would be too abundant and "senseless" precursors produced. Thus, the more TCR gene products could react with MHC molecules the more specific was thymic selection.

Jerne's hypothesis was supported by some studies, even though the efficacy of thymic selection was low (Zerrahn et al., 1997; Sebzda et al., 1999). Alloreactive T-lymphocytes could recognize determinants independent of the bound peptide (Mullbacher et al., 1991; Smith et al., 1997). Nevertheless, the bulk of data indicated that peptide-independent recognition was rare, and alloreactive cells recognized allogeneic MHC in association with the peptides (Rotzschke et al., 1990; Heath et al., 1991; Alexander-Miller et al., 1993). Dependence of alloreactive memory $\mathrm{CD}^{+}$cells on MHC-bound peptides was seen in our studies also. Memory CD8 ${ }^{+}$cells from B10. $\mathrm{D} 2(\mathrm{R} 101)\left(\mathrm{K}^{\mathrm{d}} \mathrm{I}^{\mathrm{d}} \mathrm{D}^{\mathrm{b}}\right)$ (obtained in response to EL4 thymoma $\left(\mathrm{K}^{\mathrm{b}} \mathrm{D}^{\mathrm{b}}\right)$ ) proliferated in MLR in response to heat-shocked allogeneic stimulators from $\mathrm{C} 57 \mathrm{BL} / 6\left(\mathrm{~K}^{\mathrm{b}} \mathrm{D}^{\mathrm{b}}\right)$ wild-type mice. Proliferation was abrogated if TAP knockout stimulators were used. Thus, direct recognition allogeneic cell depended on the peptides bound to this molecule (Pobezinskaya et al., 2004).

Interesting and convincing data on the role of peptides in alloreactivity were obtained in a "single MHC/ peptide" system (Kovalik et al., 2000) One study, using transgenic $p E a$ mice in which all Class II MHC were represented by the individual complex of $\mathrm{A}^{\mathrm{b}}$ with AA52-68 peptide of $\mathrm{E} \alpha$, and DM-KO mice in which Class II molecules were bound with individual CLIP peptide of the Ii invariant chain, demonstrated important mechanisms of allogeneic and allorestricted recognition. First, both ligands seemed "poor" stimulators of allogeneic responses, supporting the "frequency of determinants" hypothesis and identifying presentation of a diverse peptide repertoire for induction of intense responses. Second, T-lymphocyte hybridomas obtained in the responses to these "allorestricting complexes" were more sensitive to stimulation with antigenic peptide; these hybridomas recognized peptide in a degenerated manner unlike hybridomas from syngeneic "autorestricted" responders. Third, testing $>500$ alloreactive hybridomas showed that the majority of alloreactive T-lymphocytes depended on the peptide (only 17\% recognized this peptide specifically). The authors suggested that peptides influenced the allogeneic response by inducing weak conformational changes in the MHC molecule $\alpha$-helix, and these changes were recognized by alloreactive lymphocyte receptors. Degenerated recognition of the peptide, and high sensitivity to the peptide ligand, were key features of alloreactive T-lymphocytes.

MHC also interact with TCR; this interaction is important for alloreactivity. CTL lyse TAP- allogeneic targets that express only low amounts of the "empty" heavy chains of Class I MHC molecules. Moreover, in bm3 TAP knockout mice, $\mathrm{CD}^{+}$cells formed in the thymus and accumulated in peripheral lymphoid organs, indicating that positive 
selection could occur in an absence of bound peptide (Kuhns et al., 2000). Schneck et al. (1989a, 1989b) showed that allogeneic recognition of $\mathrm{H}-2 \mathrm{~K}^{\mathrm{b}}$ by CTL was blocked by the peptide AA163-174 of the same molecule, meaning there was a region for binding the MHC heavy chain with TCR. In our own work, peptides from C-terminal regions of $\alpha$-helices devoid of MHC binding motifs for B10.D2(R101) recipients-when injected-still induced cell-mediated suppression of allogeneic responses and extended the life span of allogeneic skin grafts in recipients (Brondz et al., 1995). Further evidence of the interaction of TCR with fragments of MHC molecules was demonstrated with mutant MHC. Some individual point mutations in the MHC side $\alpha$-helices had no effect on the spectrum of bound peptides, but caused intense immune responses (Falk et al., 1992; Grandea and Bevan, 1993). Noun et al. (1998) showed that mutations in positions $62,65,69,72,152$, 163 , and 166 in $\alpha$-helices away from the binding groove could be antigenic. The repertoire of peptides that bound individual mutants did not correlate with the ability of the mutants to evoke primary immune responses.

Still, it remained unclear which AA residues were critical for recognition of Class I MHC by alloreactive/ autorestricted CTL. Using large panels of alloreactive and autorestricted clones and targets that expressed mutated AA residues, it was shown that recognition by alloreactive and autorestricted clones depended on the same residues in the heavy chains that formed common clusters of recognition (Sun et al., 1995; Hornell et al., 1999). Ala mutagenesis-based mapping of relative energies of interaction of TCR with the MHC heavy chain revealed that $\approx 67 \%$ of the surface and energy in the interface between TCR and MHC molecules belonged to interaction of the receptors with the Class I heavy chain (Manning et al., 1998). These data indicated that alloreactivity not be explained solely by differences in the peptide repertoire presented by various MHC. Side $\alpha$-helices also play an important role being capable of direct interaction with the TCR.

MHC molecules present "self" and "alien" peptides to T-lymphocytes. The groove MHC-peptide is directed to the extracellular milieu and is a plane formed by $\alpha$-helices and the peptide. Topologically, interactions within each TCR/MHC/peptide complex are similar to those in all others, i.e., TCR is oriented diagonally to external surface of MHC/peptide complex. Spatially, the CDR1 and CDR2 of the TCR $\alpha$-chains are localized near the peptide $\mathrm{N}$-terminus, whereas similar parts of the $\beta$-chain are positioned near the $\mathrm{C}$ terminus. CDR1 and CDR2 chains encoded by the $\mathrm{V}$ region interact mainly with MHC AA residues. The third region in the TCR is most variable and determines the complementary interaction CDR3-MHC. The regions of TCR CDR3 $\alpha$ and CDR3 $\beta$ are oriented to the center of the TCR/MHC/peptide and interact mainly with the central portion of the peptide. Several residues in the peptide form the external surface of the MHC/ peptide complex and are available for interaction with the TCR. This is why the most variable regions of the TCR CDR3 $\alpha$ and CDR3 $\beta$ chains have optimal access to the most variable component of the ligand, i.e., the peptide (Garcia et al., 1996; Davis et al., 1998).

A similar principle of TCR/MHC interaction was found for allospecific TCR Bm3.3 that bind Class I H-2 $\mathrm{K}^{\mathrm{b}}$ complexed with a naturally-processed octapeptide (pBM1:INFDFNTI). In this complex, TCR and MHCbound peptide were linked via a CDR3 $\beta$ region whereas in another TCR, the $\alpha$ - and $\beta$-chains had equal impact on interactions. Accordingly, only a few C-terminus residues were involved in interactions. Another peculiarity of the complex was the very small TCR and MHC interface; this was surprising, as the affinity of interaction was very high. The CDR3 $\alpha$ region of this TCR was large and was shifted from the peptide-binding groove. This region interacted only with Gln65 of the $\alpha$-helix of the $\alpha_{1}$ domain of the MHC, whereas CDR3 $\beta$ consisted of nine residues that all interacted with the peptide. The CDR $1 \alpha$ and CDR2 $\alpha$ were shifted to the $\mathrm{N}$-terminus of the $\alpha$-helix of the $\alpha_{2}$-domain of the MHC molecule, i.e., away from the peptide binding area, which abrogated their interaction with the $\alpha$-helices. Thus, the position of the ligand-bound TCR was oblique and mediated mainly by interactions with the $\mathrm{V} \beta$ chain of the receptor with the MHC side-chain and the peptide C-terminal part. These spatial considerations were relevant to the degenerative mode of peptide recognition in the allogeneic response. For a particular TCR/MHC/peptide combination, the predicted number of peptides interacting with Bm3.3 TCR could increase 400-fold (Reiser et al., 2000).

Nevertheless, evidence supports a general degenerative recognition of $\mathrm{MHC} /$ peptide complexes by all TCR (Eisen, 2001). Usually, a detailed analysis of crossreactivity of individual TCR reveals additional MHC or peptide ligands capable of interacting with receptors of interest. Cross-reactivity was found in our studies of an alloreactive MCC- 1 clone of $\mathrm{CD}^{+}$memory cells obtained in a response to an allogeneic $\mathrm{H}-2 \mathrm{~K}^{\mathrm{b}}$ molecule. This clone could be activated by the immunizing antigen as well as in a response to $\mathrm{H}-2 \mathrm{D}^{\mathrm{d}}\left(\mathrm{L}^{\mathrm{d}}\right)$ and $\mathrm{H}-2 \mathrm{D}^{\mathrm{q}}\left(\mathrm{L}^{\mathrm{q}}\right)$. However, lengths of the CDR3 $\alpha$ and $-\beta$ chains of its TCR were similar (Pobezinskaya et al., 2004). Most likely, a degenerative manner of recognition is an important trait of the immune response that allows T-lymphocytes to recognize an enormously wide variety of MHC-bound peptides; the specificity is sufficient to discriminate between "self" and "foreign".

It can thus be concluded that there are no critical differences in recognition of a peptide in the context of syngeneic or allogeneic MHC. Both types of interaction can induce highly-specific immune responses to individual MHC/peptide complexes and are efficient in recognizing other combinations. Nevertheless, responses to 
allogeneic MHC/peptide complexes are characterized by a large number of degeneratively recognizing clones that cross-react with other MHC by interacting with their $\alpha$-helices. These clones supposedly appear since negative selection does not eliminate them.

\section{Role of MHC in immunotoxicology: recognition of xenobiotics}

In light of the increased understanding of the MHC and its role(s) in normal host immune responses, several studies have sought to determine the bases for T-lymphocytemediated phenomena like contact hypersensitivity (CHS) and allergic contact dermatitis (ACD) in response to small chemical compounds, chromium and nickel agents, as well as chronic lung beryllium disease (CBD) in response to beryllium ions.

Low-molecular chemicals with an intrinsic potential to covalently modify proteins are classified as haptens. Many are strong inducers of T-lymphocyte-mediated CHS, and hapten-specific lymphocytes are known to interact with hapten-modified MHC-associated peptides. In contrast to these classical haptens, nickel (Ni) ions do not form covalent bonds to proteins, but become caught in reversible coordination complexes. Some T-lymphocytes may react to such Ni complexes on the MHC/peptide-surface, akin to what happens with common haptens. In other cases, Ni ions may activate lymphocytes by cross-linking their receptors to MHC independent of the nature of the peptide (Thierse et al., 2004, 2005). The MHC restriction element in Ni-reactive T-lymphocytes (ANi-2.3) was designated DR52c. A series of experiments established that the functional ligand for these lymphocytes was a preformed complex of Ni bound to a combination of DR52c and a specific peptide that generated in B-lymphocytes (but not in fibroblasts or any other antigen processingdeficient cells). In addition, ANi-2.3 recognition of this complex was dependent on His81 of the MHC $\beta$-chain, suggesting a role for this AA in Ni binding to MHC. Lu et al. (2003) proposed that a general model for Ni recognition was one in which $\beta$ His81 and two AA from the $\mathrm{NH}_{2}-$ terminal part of the MHC bound peptide-coordinated Ni which, in turn, interacts with some portion of the $\mathrm{V} \alpha$ CDR1 or CDR2 region.

In another study using the T-lymphocyte clone SE9, potential Ni contact sites in the TCR and the restricting histocompatibility leukocyte antigen (HLA)-DR structure were identified. The specificity of this HLA-DR-favoring V $\alpha 22 /$ $\mathrm{V} \beta 17^{+}$TCR was primarily due to its $\alpha$-chain. Ni reactivity was neither dependent on APC protein processing nor affected by the nature of HLA-DR-associated peptides. However, SE9 activation by Ni did depend on Tyr29 in CDR1 $\alpha$, an N-nucleotide-encoded Tyr94 in CDR3 $\alpha$, and a conserved His81 in the HLA-DR $\beta$-chain. This indicated that labile non-activating complexes between SE9 TCR and most HLA-DR-peptide conjugates might be sterically optimized coordination sites for $\mathrm{Ni}$. In the complexes, $\mathrm{Ni}$ may effectively bridge the TCR $\alpha$-chain to His81 in most DR. Thus, analogous to super-antigens, Ni may link TCR to MHC in a peptide-independent manner. However, unlike super-antigens, Ni requires idiotypic (i.e., CDR3 $\alpha$ determined) TCR AAs. This novel TCR-MHC linkage might explain the high frequency of Ni-reactive T-lymphocytes in humans (Gamerdinger et al., 2003).

$\mathrm{CBD}$, a granulomatous lung disorder caused by worksite beryllium (Be), is characterized by accumulation of Be-specific CD4+ T-lymphocytes. Depending on genetic susceptibility and the nature of exposure, CBD occurs in up to $20 \%$ of exposed workers. Susceptibility has been associated with particular HLA-DP alleles, especially those possessing a negatively-charged Glu residue at AA69 of the $\beta$-chain. The basis for this association lies in the ability of these HLA-DP to bind and present Be to pathogenic $\mathrm{CD}^{+}$cells. Large numbers of effector memory, Be-specific $\mathrm{CD} 4^{+}$lymphocytes are recruited to the lung and secrete $\mathrm{T}_{\mathrm{H}} 1$-type cytokines upon Be recognition. A presence of circulating Be-specific $\mathrm{CD} 4^{+}$cells directly correlates with severity of lymphocytic alveolitis. As such, CBD serves as an important model of immunemediated organ destruction. The findings related to CBD have implications for studies of autoimmune diseases, in particular, those with unknown inciting antigens and inaccessible target organs (Amicosante and Fontenot, 2006; Newman, 2007).

Drug-induced hypersensitivity reactions have been explained by the hapten concept, i.e., a compound is too small to be recognized by the immune system. After the drug is covalently bound to an endogenous protein, the hapten-carrier complex (larger modified protein) is immunogenic to B- and T-lymphocytes. Consequently, an immune response (to the drug) with very heterogeneous clinical manifestations develops. In recent years, evidence has shown that not all drugs need covalently bind to the MHC-peptide complex in order to trigger an immune response. Rather, some may directly and reversibly bind to immune receptors like the MHC or TCR, thereby stimulating the cells similar to a pharmacological activation of other receptors. This concept has been termed "pharmacological interaction with immune receptors," the (p-i) concept.

While the exact mechanism is still a matter of debate, non-covalent drug presentation clearly leads to activation of drug-specific T-lymphocytes by various agents (e.g., lidocaine, sulfamethoxazole, lamotrigine, carbamazepine, $p$-phenylendiamine, etc.). In some patients with drug hypersensitivity, such a response may occur within hours upon first exposure to the drug. Thus, the reaction may not be due to a classic primary response but, rather, be mediated by stimulating existing pre-activated, peptide-specific lymphocytes cross-specific for the drug. 
By this, certain drugs may circumvent checkpoints in immune activation imposed by antigen processing and presentation mechanisms; this may explain the peculiar nature of many drug hypersensitivity reactions (Pichler et al., 2006).

As with indirect and direct responses to grafted tissues, the role of chemically-modified peptides (in the context of MHC molecules) as well as direct influence on TCR/ MHC interactions in these reactions can be clarified. In a structure of Class I domains recognized by TCR, AA residues have been identified that are invariant even in evolutionary-very distant species. Their location on 3D-structure models indicates that in structure-forming function, as a rule, they are located in contact sites between $\alpha$-helices and $\beta$-sheets. Studies of combinatorial homology between Class I and II molecules have identified a fragment located in a "kink"-region of both Class I (AA154-164) and $\beta$-chains of Class II molecules (AA63-73, A-molecules; AA 69-79, E molecules) at which a spectra of "allowed" AA substitutions significantly coincide. Thus, this region could play a role as "anchor" for interactions with TCR, providing the capability for the latter to distinguish MHC from other molecules (Kazanskii et al., 2004). Importantly, point mutations here result in well-known $\mathrm{K}^{\mathrm{bml}}$ and $\mathrm{A}_{\beta}^{\mathrm{bm} 12}$ molecules capable of inducing vigorous allogeneic responses in wild-type C57BL/6 mice.

Although knowledge of the details of interaction between small xenobiotics and MHC molecules is imperfect, it can be anticipated that chemical modification or acquiring reversible coordination complexes in/near a kink-region will result in highly immunogenic forms of these molecules and increased risk for development of autoimmune and allergic diseases. The involvement of His81 and Glu69 in Class II $\beta$-chains into recognition of $\mathrm{Ni}$ and Be ions may suggest this idea (Gamerdinger et al., 2003; Lu et al., 2003; Newman, 2007).

\section{Back to Jerne's hypothesis}

Is it reasonable that the ability of T-receptor repertoires to interact with MHC are genetically determined? Two groups have seen that non-selected lymphocyte receptor repertoires had an innate capability to recognize MHC in the thymus (Merkenschlager et al., 1997; Zerrahn et al., 1997). One demonstrated that $20 \%$ of thymocytes recognize MHC prior to positive and negative selection, as CD69 activation marker was expressed upon recognizing cells. The other used T-lymphocytes from mice that did not express MHC, i.e., DP lymphocytes (immature) with a receptor repertoire not positively or negatively selected for MHC. Using monoclonal antibodies against TCR $\alpha / \beta$ and CD4, maturation of the lymphocytes was induced in fetal thymic organ cultures. Analysis of TCR specificity revealed a high frequency of clones that reacted with allogeneic MHC in a pre-selected T-lymphocyte repertoire; this frequency was similar to that after selection. This indicated the innate predisposition of TCR to interact with MHC. Genes coding for TCR were evolutionary designed in a way such that their products bind predominantly with MHC side $\alpha$-helices; this is particularly true for $\mathrm{V}$-segment CDR1 and CDR2 regions.

These results were surprising. Indeed: (1) preferential interaction of TCR with the MHC is not a consequence of positive selection in a thymus; (2) the T-lymphocyte repertoire is primarily specific to all variants of classic MHC molecules, presuming a coordinated evolution of three independent genetic loci $(\alpha / \delta, \beta$, and MHC); and, (3) alloreactivity and MHC restriction can be a sequelae of this innate specificity. Yang et al. (2002) estimated there were four combinations of peptides with the $\mathrm{H}-2 \mathrm{~K}^{\mathrm{b}}$ that induced auto- and allorestricted responses in three mouse strains.

Responders were primed in vitro with stimulators loaded with peptides, followed by evaluation of frequencies of peptide specific CTL. Three out of four peptides induced responses restricted by self-MHC better than by alien MHC, but differences were only 3-5-fold. The fourth peptide induced auto- and allorestricted CTL with equal efficacy. Titration of peptides showed that high avidity CTL were present among the auto- and allorestricted CTL. The authors concluded that narrowing the repertoire to a preferential recognition of antigens in the context of self-MHC (which can be expected from positive selection in thymus) was minor. Further analysis of lectin-stimulated maturation of thymocytes from mice deficient in MHC showed that the number of $\mathrm{K}^{\mathrm{b}}$ restricted CTL among these lymphocytes was similar to the number of allorestricted CTL. Thus, MHC-restricted recognition of peptides was innate and imminent for a T-lymphocyte repertoire, and this recognition did not require thymic selection on MHC molecules.

As early as 1971, Jerne postulated the genetic predisposition of the repertoire for MHC recognition, i.e., "antibody specificity is determined by structural V-genes that code for AA sequences of variable regions on antibody polypeptide chains." The present hypothesis proposes that a host's germ-cells carry a set of V-genes determining combining sites of antibodies directed against a complete set of a given class of histocompatibility antigens of the host species. Though this hypothesis is 37 years old, its importance remains great.

\section{What is really going on?}

Much data appeared to not fit the hypothesis of ontogenetic origin of MHC restriction. Among the problems encountered has been: experiments on which the hypothesis was founded have been criticized; results in transgenic TCR hosts have been largely refuted; and, specificity of restriction by T-lymphocytes was associated 
not with the thymus, but with cells originating in the BM (minor impact from microenvironment and periphery survival). As a result, an "initial priming" hypothesis emerged that based itself on the critical role of a primary immune response to a given MHC/peptide combination. Due to this priming, a portion of the lymphocyte repertoire arose that was specific to recognition of particular MHC/peptide complexes, i.e., specificity was dictated by antigen-presenting cell. Limiting this specificity by thymic "bringing-up" to given MHC/peptide complexes resulted in a variable repertoire of T-lymphocytes capable of reacting with allogeneic MHC molecules.

Identification of MHC-binding motifs in antigenic peptides provided a structural basis for explanation of the origin of MHC restriction in terms of "initial priming." Combinatory peptide libraries proved the existence of a broad repertoire of allorestricted T-lymphocytes and revealed an insignificant role for positive selection in narrowing repertoires down to autorestricted clones. Taking into account that adaptive differentiation could not provide explanations to phenomena of allorestricted responses and direct allogeneic recognition, it was time to admit that an ontogenic origin of MHC restriction, though still predominant in immunology textbooks, was misleading. The hypothesis also tried to explain alloreactivity as cross-reactivity with "self." But for what reason were "cross-reactive" alloreactive clones not deleted during thymic negative selection? Were cross-reactions more pronounced than specific ones? The most obvious answer was no. Logic suggested that "the reaction of the repertoire to foreign transplantation antigens was specific, whereas recognition of peptides in the context of self MHC was a "cross-reaction."

Loss of some specificities potentially useful for responses to pathogens was inevitable and created an Achilles' heel in the organism being attacked. Because MHCs were highly polymorphic and their allelic forms presented different peptides from the same protein, this vulnerability was individual within a species. This was why selection of virus variants for ability to escape immunological attack in one organism would not rescue a variant from the immune system of a different host. Thus, MHC polymorphism created a safety net that allowed slowly-evolving vertebrata to survive even in the presence of quickly evolving pathogenic organisms.

The traits of the immune system used to be considered in the context of co-evolution with pathogenic microorganisms. By this, polymorphism among MHCs would mean the variability of only those AA residues responsible for peptide presentations. However, the majority of variable residues localized in TCR binding regions and had no impact on peptide binding specificity; nevertheless, these variable residues were necessary for MHC alloantigenicity. The reason for polymorphism was unclear, considering the traditional role of MHC, i.e., antigen presentation. However, the reason could be deduced based on a hypothesis that pinpointed MHC molecule alloantigenic traits. Indeed, changes in alloantigenic "image" of the molecule would change the character of negative selection of the repertoire; this would provide an opportunity to rescue individual clones that respond to the pathogen.

The proposed hypothesis seemed to both reconcile transplantation immunology with MHC restriction and explain alloreactivity, and provided a foundation for the phenomena, i.e., interaction of repertoire with histocompatibility molecules. Adaptive differentiation failed to explain alloreactivity, and even genetic control of allogeneic reactions and MHC-restricted recognition was considered differentially. The ability to induce a specific allogeneic response was inherited as a dominant trait, whereas an ability to induce MHC-restricted responses was co-dominant. To researchers of MHC-restricted recognition, allogeneic effects were distracting; genetically defined hosts were needed to avoid these. It is thus understandable that allogeneic phenomena were put aside; this situation changed after discovery of allorestricted recognition.

Jerne's hypothesis solved the enigma of dominant inheritance of alloantigenicity by linking $\mathrm{V}$ gene structures and an innate predisposition of a repertoire to recognize transplantation antigens. A precise provision of Jerne was confirmed by discovery of MHC peptide presentation in studies that showed that allelic forms of the molecules presented different peptides. Other studies proved the critical role of a broad peptide repertoire in the intensity of allogeneic responses. Overall, this hypothesis stated that "the high intensity of an allogeneic response was explainable by two non-exclusive peculiarities of T-lymphocyte recognition: (1) a genetically,determined ability of a repertoire to interact with the entire spectrum of a species' MHC; and, (2) specificity of negative selection that maintained the ability of a repertoire to respond to peptides in the context of allogeneic MHC molecules."

Apparently, the major problem for the immune system was to avoid transplantation conflict in a host. Indeed, receptors of adaptive immunity "see" selfantigens more frequently than pathogens. In any case, existence of a potentially dangerous system in the host could be no less a factor in the evolution of its immune system than the pathogen. Thus, MHC-restricted recognition could develop not as much in the struggle with pathogenic microorganisms, but in inhibiting reactions with "self." By this, restriction of immune reactions by several types of recognized molecules would be helpful. MHC have allowed the immune system to redirect these reactions to short peptides containing AA substitutions not presented in the responding organism. On the other hand, they have allowed the responding organism to form specific central tolerance to self, not involving in 
this process a huge diversity of conformations created by other proteins. As such, alloreactivity can be, not only a backstop for efficiency during induction of tolerance, but a general feature of T-lymphocyte repertoires.

One argument of adepts in differentiation was the artificial, purely laboratory character of alloreactivity, i.e., it is a phenomenon that does not exist naturally. Nevertheless, the reaction of thymocytes to self-MHC during intra-thymic selection had much in common with the reaction of a mature repertoire to transplantation antigens. Both depended on the same co-stimulatory ligands and co-receptors (Punt et al., 1994, 1997), and avidity of T-lymphocyte-APC interactions - although the threshold of activation for thymocytes seemed to be lower than that of mature peripheral lymphocytes (Ashton-Rickardt et al., 1994; Sebzda et al., 1994). Clearly, positive selection could be an analog of peripheral interactions of T-lymphocytes with self-MHC necessary for survival (Viret and Janeway, 1999). Intra-thymic negative selection was evidently similar to deletion of peripheral T-lymphocytes upon binding of endogenous superantigens (Chervonsky et al., 1995). A significant difference was that thymocyte interactions with self-MHC led to deletion of the former, whereas mature lymphocytes gained effector functions after reaction to alloantigen (Pircher et al., 1991). Thus, thymic selection could be considered first and last as a lifelong allogeneic reaction of pre-selected repertoire to self-transplantation antigens.

The goal of this review was to illustrate conflicts among the modern theories of MHC restriction and allogeneic recognition, and to present an alternative concept that reconciled these views. The ideas expressed here were initiated by those of Jerne (1971) and the findings of Zerrahn and Raulet (1997), as well as of those that subsequently evolved (Janeway et al., 1997; Viret and Janeway, 1999; Huseby et al., 2003, 2004; Whitelegg and Barber, 2004).

\section{References}

Alexander-Miller, M. A., Burke, K., Koszinowski, U. H., Hansen, T. H., and Connolly, J. M. 1993. Alloreactive cytotoxic T-lymphocytes generated in the presence of viral-derived peptides show exquisite peptide and MHC specificity. J. Immunol. 151:1-10.

Amicosante M., and Fontenot, A. P. 2006. T-Cell recognition in chronic beryllium disease. Clin. Immunol. 121:134-143.

Amrolia, P. J., Reid, S. D., Gao, L., Schultheis, B., Dotti, G., Brenner, M. K., Melo, J. V., Goldman, J. M., and Stauss, H. J. 2003. Allorestricted cytotoxic T-cells specific for human CD45 show potent anti-leukemic activity. Blood 101:1007-1014.

Arsov, I., and Vukmanovic, S. 1999. Dual MHC Class I and Class II restriction of a single T-cell receptor: Distinct modes of tolerance induction by two classes of autoantigens. J. Immunol. 162:2008-2015.

Ashton-Rickardt, P. G., Bandeira, A., Delaney, J. R., Van Kaer, L., Pircher, H. P., Zinkernagel, R. M., and Tonegawa, S. 1994. Evidence for a differential avidity model of T-cell selection in the thymus. Cell 76: 651-663.

Babbitt, B. P., Allen, P. M., Matsueda, G., Haber, E., and Unanue, E. R. 1985. Binding of immunogenic peptides to Ia histocompatibility molecules. Nature 317:359-361.
Benichou, G., Valujskikh, A., and Heeger, P. S. 1999. Contributions of direct and indirect T-cell alloreactivity during allograft rejection in mice. J. Immunol. 162:352-358.

Berg, L. J., Pullen, A. M., Fazekas de St. Groth, B., Mathis, D., Benoist, C., and Davis, M. M. 1989. Antigen/MHC-specific T-cells are preferentially exported from the thymus in the presence of their MHC ligand. Cell 58:1035-1046.

Bevan, M. J. 1975. The major histocompatibility complex determines susceptibility to cytotoxic T-cells directed against minor histocompatibility antigens. J. Exp. Med. 142:1349-1364.

Bevan, M. J. 1976. Cross-priming for a secondary cytotoxic response to minor $\mathrm{H}$ antigens with $\mathrm{H}-2$ congenic cells which do not cross-react in the cytotoxic assay. J. Exp. Med. 143:1283-1288.

Bevan, M. J. 1977. In a radiation chimera, host H-2 antigens determine immune responsiveness of donor cytotoxic cells. Nature 269:417-418.

Bix, M., and Raulet, D. 1992. Inefficient positive selection of T-cells directed by hematopoietic cells. Nature 359:330-333.

Blackman, M. A., Marrack, P., and Kappler, J. 1989. Influence of the major histocompatibility complex on positive thymic selection of $\mathrm{V} \beta 17 \alpha^{+}$ T-cells. Science 244:214-217.

Blanden, R. V., Doherty, P. C., Dunlop, M. B., Gardner, I. D., Zinkernagel, R. M., and David, C. S. 1975. Genes required for cytotoxicity against virus-infected target cells in $\mathrm{K}$ and $\mathrm{D}$ regions of $\mathrm{H}-2$ complex. Nature 254:269-270.

Bogen, B., Gleditsch, L., Weiss, S., and Dembic, Z. 1992. Weak positive selection of transgenic $\mathrm{T}$-cell receptor-bearing thymocytes: Importance of major histocompatibility complex Class II, T-cell receptor and CD4 surface molecule densities. Eur. J. Immunol. 22:703-709.

Brondz, B. D., Kazansky, D. B., Chernysheva, A. D., and Ivanov, V. S. 1995. Peptides of a major histocompatibility complex Class $I\left(K^{b}\right)$ molecule cause prolongation of skin graft survival and induce specific downregulatory T-cells demonstrable in the mixed lymphocyte reaction. Immunology 86:219-223.

Buus, S., Colon, S., Smith, C., Freed, J. H., Miles, C., and Grey, H. M. 1986. Interaction between a "processed" ovalbumin peptide and Ia molecules. Proc. Natl. Acad. Sci. USA 83:3968-3971.

Chervonsky, A. V., Golovkina, T. V., Ross, S. R., and Janeway, C. A., Jr. 1995. Differences in the avidity of TCR interactions with a superantigenic ligand affect negative selection but do not allow positive selection. J. Immunol. 155:5115-5123.

Chmielowski, B., Muranski, P., and Ignatowicz, L. 1999. In the normal repertoire of $\mathrm{CD}^{+} \mathrm{T}$-cells, a single Class II MHC/peptide complex positively selects TCR with various antigen specificities. J. Immunol. 162:95-105.

Cosgrove, D., Gray, D., Dierich, A., Kaufman, J., Lemeur, M., Benoist, C., and Mathis, D. 1991. Mice lacking MHC Class II molecules. Cell 66:1051-1066.

Davis, M. M., Boniface, J. J., Reich, Z., Lyons, D., Hampl, J., Arden, B., and Chien, Y. 1998. Ligand recognition by $\alpha \beta$ T-cell receptors. Annu. Rev. Immunol. 16:523-544.

Eisen, H. N. 2001. Specificity and degeneracy in antigen recognition: Yin and yang in the immune system. Annu. Rev. Immunol. 19:1-21.

Falk, K., Rotzschke, O., and Rammensee, H. G. 1990. Cellular peptide composition governed by major histocompatibility complex Class I molecules. Nature 348:248-251.

Falk, K., Rotzschke, O., and Rammensee, H. G. 1992. A self peptide naturally presented by both $\mathrm{H}-2 \mathrm{~Kb}$ and $\mathrm{H}-2 \mathrm{Kbm} 1$ molecules demonstrates MHC restriction of self tolerance at the molecular level. Int. Immunol. 4:321-325.

Falk, K., Rotzschke, O., Deres, K., Metzger, J., Jung, G., and Rammensee, H. G. 1991a. Identification of naturally processed viral nonapeptides allows their quantification in infected cells and suggests an allele-specific T-cell epitope forecast. J. Exp. Med. 174:425-434.

Falk, K., Rotzschke, O., Stevanovic, S., Jung, G., and Rammensee, H. G. 1991b. Allele-specific motifs revealed by sequencing of self-peptides eluted from MHC molecules. Nature 351:290-296.

Fischer Lindahl, K., and Wilson, D. B. 1977. Histocompatibility antigenactivated cytotoxic T lymphocytes II. Estimates of frequency and specificity of precursors. J. Exp. Med. 145:508-522.

Gallimore, A., Dumrese, T., Hengartner, H., Zinkernagel, R. M., and Rammensee, H. G. 1998. Protective immunity does not correlate with the hierarchy of virus-specific cytotoxic T-cell responses to naturally processed peptides. J. Exp. Med. 187:1647-1657. 
Gamerdinger, K., Moulon, C., Karp, D. R., Van Bergen, J., Koning, F., Wild, D., Pflugfelder, U., and Weltzien, H. U. 2003. A new type of metal recognition by human T-cells: Contact residues for peptideindependent bridging of T-cell receptor and major histocompatibility complex by nickel. J. Exp. Med. 197:1345-1353.

Gao, L., Bellantuono, I., Elsasser, A., Marley, S. B., Gordon, M. Y., Goldman, J. M., and Stauss, H. J. 2000. Selective elimination of leukemic $\mathrm{CD}^{+} 4^{+}$progenitor cells by cytotoxic T-lymphocytes specific for WT1. Blood 95:2198-2203.

Garcia, K. C., Degano, M., Stanfield, R. L., Brunmark, A., Jackson, M. R., Peterson, P. A., Teyton, L., and Wilson, A. 1996. An $\alpha \beta$ T-cell receptor structure at $2.5 \mathrm{~A}^{\circ}$ and its orientation in the TCR-MHC complex. Science 274:209-219.

Golovkina, T., Agafonova, Y., Kazansky, D., and Chervonsky, A. 2001. Diverse repertoire of the MHC Class II-peptide complexes is required for presentation of viral superantigens. J. Immunol. 166:2244-2250.

Gordon, R. D., Simpson, E., and Samelson, L. E. 1975. In vitro cell-mediated immune responses to the male specific (H-Y) antigen in mice. J. Exp. Med. 142:1108-1120.

Gould, D. S., and Auchincloss, H., Jr. 1999. Direct and indirect recognition: The role of MHC antigens in graft rejection. Immunol. Today 20:77-82.

Grandea, A. G., and Bevan, M. J. 1993. A conservative mutation in a Class I MHC molecule outside the peptide binding groove stimulates responses to self peptides. J. Immunol. 151:3981-3987.

Grusby, M. J., Johnson, R. S., Papaioannou, V. E., and Glimcher, L. H. 1991. Depletion of CD4 ${ }^{+}$T-cells in major histocompatibility complex Class II-deficient mice. Science 253:1417-1420.

Heath, W. R., Kane, K. P., Mescher, M. F., and Sherman, L. A. 1991. Alloreactive T-cells discriminate among a diverse set of endogenous peptides. Proc. Natl. Acad. Sci. USA 88:5101-5105.

Hornell, T. M., Solheim, J. C., Myers, N. B., Gillanders, W. E., Balendiran, G. K., Hansen, T. H., and Connolly, J. M. 1999. Alloreactive and syngeneic CTL are comparably dependent on interaction with MHC Class I $\alpha$-helical residues. J. Immunol. 163:3217-3225.

Hugo, P., Kappler, J. W., McCormack, J. E., and Marrack, P. 1993. Fibroblasts can induce thymocyte positive selection in vivo. Proc. Natl. Acad. Sci. USA 90:10335-10339.

Huseby, E. S., Crawford, F., White, J., Kappler, J., and Marrack, P. 2003. Negative selection imparts peptide specificity to the mature T-cell repertoire. Proc. Natl. Acad. Sci. USA 100:11565-11570.

Huseby, E., Kappler, J., and Marrack, P. 2004. TCR-MHC/peptide interactions: Kissing-cousins or a shotgun wedding? Eur. J. Immunol. 34:1243-1250.

Ignatowicz, L., Kappler, J., and Marrack, P. 1996. The repertoire of T-cells shaped by a single MHC/peptide ligand. Cell 84:521-529.

Ignatowicz, L., Rees, W., Pacholczyk, R., Ignatowicz, H., Kushnir, E., Kappler, J., and Marrack, P. 1997. T-Cells can be activated by peptides that are unrelated in sequence to their selecting peptide. Immunity 7:179-186.

Janeway, C. A., Chervonsky, A. V., and Sant'Angelo, D. 1997. T-cell receptors: Is the repertoire inherently MHC-specific? Curr. Biol. 7:299-300.

Jerne, N. K. 1971. The somatic generation of immune recognition. Eur. J. Immunol. 1:1-9.

Kabelitz, D., Herzog, W. R., Heeg, K., Wagner, H., and Reimann, J. 1987. Human cytotoxic T-lymphocytes. III. Large numbers of periphera blood T-cells clonally develop into allo-restricted anti-viral cytotoxic T-cell populations in vitro. J. Mol. Cell. Immunol. 3:49-60.

Kalbus, M., Fleckenstein, B. T., Offenhausser, M., Bluggel, M., Melms, A., Meyer, H. E., Rammensee, H. G., Martin, R., Jung, G., and Sommer, N. 2001. Ligand motif of the autoimmune disease-associated mouse MHC Class II molecule H2-A(s). Eur. J. Immunol. 31:551-562.

Katz, D. H. 1977. The role of histocompatibility complex in lymphocyte differentiation. Cold Spring Harbor Symp. Quant. Biol. 41:611-624.

Kaye, J., Hsu, M. L., Sauron, M. E., Jameson, S. C., Gascoigne, N. R., and Hedrick, S. M. 1989. Selective development of CD4 ${ }^{+}$T-cells in transgenic mice expressing a Class II MHC-restricted antigen receptor. Nature 341:746-749.

Kaye, J., Vasquez, N. J., and Hedrick, S. M. 1992. Involvement of the same region of the T-cell antigen receptor in thymic selection and foreign peptide recognition. J. Immunol. 148:3342-3353.
Kazanskii, D. B., Pobezinskii, L. A., and Tereshchenko, T. S. 2004. Motifs in the primary structure of MHC Class I molecules and their use for the design of synthetic T-cell receptor ligands. Vestn. Ross. Akad. Med. Nauk. 12:25-32.

Kazansky, D. B., Chernysheva, A. D., Sernova, N. V., Petrishchev, V. N., Pobezinskii, L. A., Agafonova, E. L., and Chervonskii, A. V. 1998. The nature of epitopes, recognized by T-lymphocytes in the allogeneic immune response. Mol. Biol. (Mosk). 32:692-702.

Kazansky, D. B., Petrishchev, V. N., Shtil', A. A., Chernysheva, A. D., Sernova, N. V., Abronina, I. F., Pobezinskii, L. A., and Agafonova, E. L. 1999. Use of heat shock of antigen-presenting cells for functional testing of allospecific memory T-cells. Bioorg. Khim. 25:117-128.

Kirberg, J., Baron, A., Jakob, S., Rolink, A., Karjalainen, K., and von Boehmer, H. 1994. Thymic selection of $\mathrm{CD}^{+}$single positive cells with a Class II major histocompatibility complex-restricted receptor. J. Exp. Med. 180:25-34.

Kisielow, P., Teh, H. S., Bluthmann, H., and von Boehmer, H. 1988. Positive selection of antigen-specific T-cells in thymus by restricting MHC molecules. Nature 335:730-733.

Koller, B. H., Marrack, P., Kappler, J. W., and Smithies, O. 1990. Normal development of mice deficient in $\beta_{2} \mathrm{M}$, MHC Class I proteins, and CD8+ T-cells. Science 248:1227-1229.

Koszinowski, U., and Ertl, H. 1975. Lysis mediated by T-cells and restricted by $\mathrm{H}-2$ antigen of target cells infected with vaccinia virus. Nature 255:552-554.

Kovalik, J. P., Singh, N., Mendiratta, S. K., Martin, W. D., Ignatowicz, L., and Van Kaer, L. 2000. The alloreactive and self-restricted CD4 ${ }^{+}$ $\mathrm{T}$-cell response directed against a single MHC Class II/peptide combination. J. Immunol. 165:1285-1293.

Kuhns, S. T., Tallquist, M. D., Johnson, A. J., Mendez-Fernandez, Y., and Pease, L. R. 2000. T-Cell receptor interactions with Class I heavy-chain influence T-cell selection. Proc. Natl. Acad. Sci. USA 97:756-760.

Lee, D. S., Ahn, C., Ernst, B., Sprent, J., and Surh, C. D. 1999. Thymic selection by a single $\mathrm{MHC} /$ peptide ligand: Autoreactive T-cells are lowaffinity cells. Immunity 10:83-92.

Logunova, N. N., Viret, C., Pobezinsky, L. A., Miller, S. A., Kazansky, D. B., Sundberg, J. P., and Chervonsky, A. V. 2005. Restricted MHC-peptide repertoire predisposes to autoimmunity. J. Exp. Med. 202:73-84.

Longo, D. L., and Schwartz, R. H. 1980. T-cell specificity for H-2 and Ir gene phenotype correlates with the phenotype of thymic antigenpresenting cells. Nature 287:44-46.

Lu, L., Vollmer, J., Moulon, C., Weltzien, H. U., Marrack, P., and Kappler, J. 2003. Components of the ligand for a $\mathrm{Ni}^{2+}$ reactive human $\mathrm{T}$-cell clone. J. Exp. Med. 197:567-574.

MacDonald, H. R., Lees, R. K., Schneider, R., Zinkernagel, R. M., and Hengartner, H. 1988. Positive selection of CD4 $4^{+}$thymocytes controlled by MHC Class II gene products. Nature 336:471-473.

Manning, T. C., Schlueter, C. J., Brodnicki, T. C., Parke, E. A., Speir, J. A., Garcia, K. C., Teyton, L., Wilson, I. A., and Kranz, D. M. 1998. Alanine scanning mutagenesis of an $\alpha \beta$ T-cell receptor: Mapping the energy of antigen recognition. Immunity 8:413-425.

Marrack, P., Kushnir, E., Born, W., McDuffie, M., and Kappler, J. 1988. The development of helper T-cell precursors in mouse thymus. $J$. Immunol. 140:2508-2514.

Martinic, M. M., Rulicke, T., Althage, A., Odermatt, B., Hochli, M., Lamarre, A., Dumrese, T., Speiser, D. E., Kyburz, D., Hengartner, H., and Zinkernagel, R. M. 2003. Efficient T-cell repertoire selection in tetraparental chimeric mice independent of thymic epithelial MHC. Proc. Natl. Acad. Sci. USA 100:1861-1866.

Marusic-Galesic, S., Longo, D. L., and Kruisbeek, A. M. 1989. Preferential differentiation of T-cell receptor specificities based on the MHC glycoproteins encountered during development. Evidence for positive selection. J. Exp. Med. 169:1619-1630.

Maryanski, J. L., Pala, P., Corradin, G., Jordan, B. R., and Cerottini, J. C. 1986. H-2-restricted cytolytic T-cells specific for HLA can recognize a synthetic HLA peptide. Nature 324:578-579.

Matechak, E. O., Killeen, N., Hedrick, S. M., and Fowlkes, B. J. 1996. MHC Class II-specific T-cells can develop in the CD8 lineage when CD4 is absent. Immunity 4:337-347.

Merkenschlager, M., Graf, D., Lovatt, M., Bommhardt, U., Zamoyska, R., and Fisher, A.G 1997. How many thymocytes audition for selection? J. Exp. Med. 186:1449-1158. 
Moris, A., Teichgraber, V., Gauthier, L., Buhring, H. J., and Rammensee, H. G. 2001. Cutting edge: Characterization of allorestricted and peptide-selective alloreactive T-cells using HLA-tetramer selection. $J$. Immunol. 166:4818-4821.

Mullbacher, A., Hill, A. B., Blanden, R. V., Cowden, W. B., King, N. J., and Hla, R. T. 1991. Alloreactive cytotoxic T-cells recognize MHC Class I antigen without peptide specificity. J. Immunol. 147:1765-1772.

Munz, C., Hofmann, M., Yoshida, K., Moustakas, A. K., Kikutani, H., Stevanovic, S., Papadopoulos, G. K., and Rammensee, H. G. 2002. Peptide analysis, stability studies, and structural modeling explain contradictory peptide motifs and unique properties of the NOD mouse MHC Class II molecule H2-A ${ }^{\mathrm{g} 7}$. Eur. J. Immunol. 32:2105-2116.

Newman, L. S. 2007. Immunotoxicology of beryllium lung disease. Environ. Health Prevent. Med. 12:161-164.

Noun, G., Reboul, M., Abastado, J. P., Kourilsky, P., Sigaux, F., and Pla, M. 1998. Strong alloantigenicity of the $\alpha$-helices residues of the MHC Class I molecule. J. Immunol. 161:148-153.

Obst, R., Munz, C., Stevanovic, S., and Rammensee, H.G. 1998. Allo- and self-restricted cytotoxic T-lymphocytes against a peptide library: Evidence for a functionally diverse allorestricted T-cell repertoire. Eur. J. Immunol. 28:2432-2443.

Obst, R., Netuschil, N., Klopfer, K., Stevanovic, S., and Rammensee, H. G. 2000. The role of peptides in T-cell alloreactivity is determined by self-major histocompatibility complex molecules. J. Exp. Med. 191:805-812.

Pichler, W. J., Beeler, A., Keller, M., Lerch, M., Posadas, S., Schmid, D., Spanou, Z., Zawodniak, A., and Gerber, B. 2006. Pharmacological interaction of drugs with immune receptors: The $\mathrm{p}$-i concept. Allergol. Int. 55:17-25.

Pircher, H., Rohrer, U. H., Moskophidis, D., Zinkernagel, R. M., and Hengartner, H. 1991. Lower receptor avidity required for thymic clonal deletion than for effector T-cell function. Nature 351:482-485.

Pobezinskaya, E. L., Pobezinskii, L. A., Silaeva, Y. Y., Anfalova, T. V., Khromykh, L. M., Tereshchenko, T. S., Zvezdova, E. S., and Kazanskii,D. B. 2004. Cross-reactivity of T-cell receptor on memory $\mathrm{CD}^{+}$cells isolated after immunization with allogeneic tumor cells. Bull. Exp. Biol. Med. 137:493-498.

Punt, J. A., Havran, W., Abe, R., Sarin, A., and Singer, A. 1997. T-cell receptor (TCR)-induced death of immature $\mathrm{CD} 4^{+} \mathrm{CD} 8^{+}$thymocytes by two distinct mechanisms differing in their requirement for $\mathrm{CD} 28 \mathrm{co}-$ stimulation: Implications for negative selection in the thymus. J. Exp. Med. 186:1911-1922.

Punt, J. A., Osborne, B. A., Takahama, Y., Sharrow, S. O., and Singer, A. 1994. Negative selection of $\mathrm{CD} 4^{+} \mathrm{CD}^{+}$thymocytes by T-cell receptorinduced apoptosis requires a co-stimulatory signal that can be provided by CD28. J. Exp. Med. 179:709-713.

Rammensee, H. G. 1995. Chemistry of peptides associated with MHC Class I and Class II molecules. Curr. Opin. Immunol. 7:85-96.

Rammensee, H. G., Falk, K., and Rotzschke, O. 1993. Peptides naturally presented by MHC Class I molecules. Annu. Rev. Immunol. 11:213-244.

Reimann, J., Heeg, K., Miller, R. G., and Wagner, H. 1985a. Alloreactive cytotoxic T-cells. I. Alloreactive and allorestricted cytotoxic T-cells. Eur. J. Immunol. 15:387-393.

Reimann, J., Kabelitz, D., Heeg, K., and Wagner, H. 1985b. Allorestricted cytotoxic T-cells. Large numbers of allo- $\mathrm{H}-2 \mathrm{~K}^{\mathrm{b}}$-restricted antihapten and antiviral cytotoxic T-cell populations clonally develop in vitro from murine splenic precursor T-cells. J. Exp. Med. 162:592-606.

Reiser, J. B., Darnault, C., Guimezanes, A., Gregoire, C., Mosser, T., SchmittVerhulst, A. M., Fontecilla-Camps, J. C., Malissen, B., Housset, D., and Mazza, G. 2000. Crystal structure of a T-cell receptor bound to an allogeneic MHC molecule. Nat. Immunol. 1:291-297.

Rotzschke, O., Falk, K., Deres, K., Schild, H., Norda, M., Metzger, J., Jung, G., and Rammensee, H. G. 1990. Isolation and analysis of naturally processed viral peptides as recognized by cytotoxic T-cells. Nature 348:252-254.

Rotzschke, O., Falk, K., Stevanovic, S., Jung, G., Walden, P., and Rammensee, H.G. 1991. Exact prediction of a natural T-cell epitope. Eur. J. Immunol. 21:2891-2894.

Sadovnikova, E., and Stauss, H. J. 1996. Peptide-specific cytotoxic T-lymphocytes restricted by nonself major histocompatibility complex Class I molecules: Reagents for tumor immunotherapy. Proc. Natl. Acad. Sci. USA 93:13114-13118.

Sadovnikova, E., Jopling, L. A., Soo, K. S., and Stauss, H. J. 1998. Generation of human tumor-reactive cytotoxic T-cells against peptides presented by non-self HLA Class I molecules. Eur. J. Immunol. 28:193-200.

Sadovnikova, E., Parovichnikova, E. N., Savchenko, V. G., Zabotina, T., and Stauss, H. J. 2002. The CD68 protein as a potential target for leukaemia-reactive CTL. Leukemia 16:2019-2026.

Schneck, J., Maloy, W. L., Coligan, J. E., and Margulies, D. H. 1989a. Inhibition of an allospecific T-cell hybridoma by soluble Class I proteins and peptides: Estimation of the affinity of a T-cell receptor for MHC. Cell 56:47-55.

Schneck, J., Munitz, T., Coligan, J. E., Maloy, W. L., Margulies, D. H., and Singer, A. 1989b. Inhibition of allorecognition by an $\mathrm{H}_{-}-\mathrm{K}^{\mathrm{b}}$ derived peptide is evidence for a T-cell binding region on a major histocompatibility complex molecule. Proc. Natl. Acad. Sci. USA 86:8516-8520.

Schwartz, R. H. 1984. The role of gene products of the major histocompatibility complex in T-cell activation and cellular interactions. In: Fundamental Immunology (Paul, W. E., Ed.), New York: Raven Press, pp. 385-392.

Sebzda, E., Mariathasan, S., Ohteki, T., Jones, R., Bachmann, M. F., and Ohashi, P. S. 1999. Selection of the T-cell repertoire. Annu. Rev. Immunol. 17:829-874.

Sebzda, E., Wallace, V. A., Mayer, J., Yeung, R. S., Mak, T. W., and Ohashi, P. S. 1994. Positive and negative thymocyte selection induced by different concentrations of a single peptide. Science 263:1615-1618.

Sha, W. C., Nelson, C. A., Newberry, R. D., Kranz, D. M., Russell, J. H., and Loh, D. Y. 1988. Positive and negative selection of an antigen receptor on T-cells in transgenic mice. Nature 336:73-76.

Sha, W. C., Nelson, C. A., Newberry, R. D., Pullen, J. K., Pease, L. R., Russell, J. H., and Loh, D. Y. 1990. Positive selection of transgenic receptor-bearing thymocytes by $\mathrm{K}^{\mathrm{b}}$ antigen is altered by $\mathrm{K}^{\mathrm{b}}$ mutations that involve peptide binding. Proc. Natl. Acad. Sci. USA 87:6186-6190.

Shearer, G. M. 1974. Cell-mediated cytotoxicity to trinitrophenyl-modified syngeneic lymphocytes. Eur. J. Immunol. 4:527-533.

Smith, P. A., Brunmark, A., Jackson, M. R., and Potter, T. A. 1997. Peptideindependent recognition by alloreactive cytotoxic $\mathrm{T}$ lymphocytes (CTL). J. Exp. Med. 185:1023-1033.

Stanislawski, T., Voss, R. H., Lotz, C., Sadovnikova, E., Willemsen, R. A., Kuball, J., Ruppert, T., Bolhuis, R. L., Melief, C. J., Huber, C., Stauss, H. J., and Theobald, M. 2001. Circumventing tolerance to a human MDM2-derived tumor antigen by TCR gene transfer. Nat. Immunol. 2:962-970.

Stockinger, H., Bartlett, R., Pfizenmaier, K., Rollinghoff, M., and Wagner, H. 1981. H-2 Restriction as a consequence of intentional priming: Frequency analysis of alloantigen-restricted trinitrophenyl-specific cytotoxic T-lymphocyte precursors within thymocytes of normal mice. J. Exp. Med. 153:1629-1639.

Stockinger, H., Pfizenmaier, K., Hardt, C., Rodt, H., Rollinghoff, M., and Wagner, H. 1980. H-2 restriction as a consequence of intentional priming: T-Cells of fully allogeneic chimeric mice as well as of normal mice respond to foreign antigens in the context of $\mathrm{H}-2$ determinants not encountered on thymic epithelial cells. Proc. Natl. Acad. Sci. USA 77:7390-7394.

Sun, R., Shepherd, S. E., Geier, S. S., Thomson, C. T., Sheil, J. M., and Nathenson, S. G. 1995. Evidence that the antigen receptors of cytotoxic T-lymphocytes interact with a common recognition pattern on the $\mathrm{H}-2 \mathrm{~K}^{\mathrm{b}}$ molecule. Immunity 3:573-582.

Takahama, Y., Suzuki, H., Katz, K. S., Grusby, M. J., and Singer, A. 1994. Positive selection of $\mathrm{CD}^{+}{ }^{+} \mathrm{T}$-cells by TCR ligation without aggregation even in the absence of MHC. Nature 371:67-70.

Tallquist, M. D., Weaver, A. J., and Pease, L. R. 1998. Degenerate recognition of alloantigenic peptides on a positive-selecting Class I molecule. J. Immunol. 160:802-809.

Tallquist, M. D., Yun, T. J., and Pease, L. R. 1996. A single T-cell receptor recognizes structurally distinct $\mathrm{MHC} /$ peptide complexes with high specificity. J. Exp. Med. 184:1017-1026.

Teh, H. S., Bennink, J., and Von Boehmer, H. 1982. Selection of the T-cell repertoire during ontogeny: Limiting dilution analysis. Eur. J. Immunol. 12:887-892.

Teh, H. S., Kisielow, P., Scott, B., Kishi, H., Uematsu, Y., Bluthmann, H., and von Boehmer, H. 1988. Thymic major histocompatibility 
complex antigens and the $\alpha \beta$ T-cell receptor determine the CD4/ CD8 phenotype of T-cells. Nature 335:229-233.

Thierse, H. J., Gamerdinger, K., Junkes, C., Guerreiro, N., and Weltzien, H. U. 2005. T-Cell receptor (TCR) interaction with haptens: Metal ions as non-classical haptens. Toxicology 209:101-107.

Thierse, H. J., Moulon, C., Allespach, Y., Zimmermann, B., Doetze, A., Kuppig, S., Wild, D., Herberg, F., and Weltzien, H. U. 2004. Metalprotein complex-mediated transport and delivery of $\mathrm{Ni}^{2+}$ to TCR/ MHC contact sites in nickel-specific human T-cell activation. J. Immunol. 172:1926-1934.

Townsend, A. R., Rothbard, J., Gotch, F. M., Bahadur, G., Wraith, D., and McMichael, A. J. 1986. The epitopes of influenza nucleoprotein recognized by cytotoxic T-lymphocytes can be defined with short synthetic peptides. Cell 44:959-968.

Udaka, K., Tsomides, T. J., and Eisen, H. N. 1992. A naturally occurring peptide recognized by alloreactive $\mathrm{CD}^{+}$cytotoxic lymphocytes in association with a Class I MHC protein. Cell 69:989-998.

Udaka, K., Wiesmuller, K. H., Kienle, S., Jung, G., and Walden, P. 1996. Self-MHC-restricted peptides recognized by an alloreactive T-lymphocyte clone. J. Immunol. 157:670-678.

Vartdal, F., Johansen, B. H., Friede, T., Thorpe, C. J., Stevanovic, S. Eriksen, J. E., Sletten, K., Thorsby, E., Rammensee, H. G., and Sollid, L. M. 1996. The peptide binding motif of the disease associated HLA-DQ $\left(\alpha 1^{*} 0501, \beta 1^{*} 0201\right)$ molecule. Eur. J. Immunol. 26:2764-2772.

Viret, C., and Janeway, C. A., Jr. 1999. MHC and T-cell development. Rev. Immunogenet. 1:91-104.

Wagner, H., Hardt, C., Bartlett, R., Stockinger, H., Rollinghoff, M., Rodt, H. and Pfizenmaier, K. 1981. Frequency analysis of cytotoxic T lymphocyte precursors in chimeric mice. Evidence for intra-thymic maturation of clonally distinct self-major histocompatibility complex- and allo-major histocompatiblilty complex-restricted virus-specific T-cells. J. Exp. Med. 153:1517-1532.

Wallny, H. J., Deres, K., Faath, S., Jung, G., Van Pel, A., Boon, T., and Rammensee, H. G. 1992. Identification and quantification of a naturally presented peptide as recognized by cytotoxic T-lymphocytes specific for an immunogenic tumor variant. Int. Immunol. 4:1085-1090.

Whitelegg, A., and Barber, L. D. 2004. The structural basis of T-cell allorecognition. Tissue Antigens 63:101-108.

Yang, T. H., Lovatt, M., Merkenschlager, M., and Stauss, H. J. 2002. Comparison of the frequency of peptide-specific cytotoxic T-lymphocytes restricted by self- and allo-MHC following in vitro T-cell priming. Int. Immunol. 14:1283-1290.

Zerrahn, J., Held, W., and Raulet, D. H. 1997. The MHC reactivity of the T-cell repertoire prior to positive and negative selection. Cell 88:627-636.

Zijlstra, M., Bix, M., Simister, N. E., Loring, J. M., Raulet, D. H., and Jaenisch, R. 1990. $\beta_{2}$-Microglobulin-deficient mice lack CD4-8 ${ }^{+}$ cytolytic T-cells. Nature 344:742-746.

Zinkernagel, R. M., and Althage, A. 1999. On the role of thymic epithelium vs. bone marrow-derived cells in repertoire selection of T-cells. Proc. Natl. Acad. Sci. USA 96:8092-8097.

Zinkernagel, R. M., and Doherty, P. C. 1973. Cytotoxic thymus-derived lymphocytes in cerebrospinal fluid of mice with lymphocytic choriomeningitis. J. Exp. Med. 138:1266-1269.

Zinkernagel, R. M., and Doherty, P. C. 1974. Restriction of in vitro T-cellmediated cytotoxicity in lymphocytic choriomeningitis within a syngeneic or semi-allogeneic system. Nature 248:701-702.

Zinkernagel, R. M., Klein, P. A., and Klein, J. 1978. Host-determined T-cell fine specificity for self $\mathrm{H}-2$ in radiation bone-marrow chimera of C57BL/6 $\left(\mathrm{H}-2^{\mathrm{b}}\right)$, mutant $\mathrm{Hzl}\left(\mathrm{H}-2^{\mathrm{ba}}\right)$, and $\mathrm{F}_{1}$ mice. Immunogenetics 7:73-77. 